\title{
Challenges for continuous graphene as a corrosion barrier
}

\author{
Camilli, Luca; Yu, Feng; Cassidy, Andrew; Hornekær, Liv; Bøggild, Peter
}

Published in:

2D materials

Link to article, DOI:

$10.1088 / 2053-1583 / a b 04 d 4$

Publication date:

2019

Document Version

Peer reviewed version

Link back to DTU Orbit

Citation (APA):

Camilli, L., Yu, F., Cassidy, A., Hornekær, L., \& Bøggild, P. (2019). Challenges for continuous graphene as a corrosion barrier. 2D materials, 6(2), [022002]. https://doi.org/10.1088/2053-1583/ab04d4

\section{General rights}

Copyright and moral rights for the publications made accessible in the public portal are retained by the authors and/or other copyright owners and it is a condition of accessing publications that users recognise and abide by the legal requirements associated with these rights.

- Users may download and print one copy of any publication from the public portal for the purpose of private study or research.

- You may not further distribute the material or use it for any profit-making activity or commercial gain

- You may freely distribute the URL identifying the publication in the public portal

If you believe that this document breaches copyright please contact us providing details, and we will remove access to the work immediately and investigate your claim 


\section{Challenges for continuous graphene as a corrosion barrier}

L. Camilli ${ }^{1}$, F. Yu$^{1}$, A. Cassidy ${ }^{2}$, L. Hornekær ${ }^{2}$ and P. Bøggild ${ }^{1}$

1. Department of Micro- and Nanotechnology, Center for Nanostructured Graphene (CNG), Technical University of Denmark, Ørsteds Plads 345C, Kongens Lyngby, 2800, Denmark

2. Department of Physics and Astronomy and Interdisciplinary Nanoscience Center iNANO, Aarhus University, Aarhus C 8000, Denmark

Email: 1cam@nanotech.dtu.dk (LC); peter.boggild@nanotech.dtu.dk (PB)

\section{Abstract}

Corrosion, the degradation of metals and alloys by chemical and/or electrochemical means, is a great challenge to the society, its industries and its citizens, both in terms of economics, safety and health. Corrosion barrier technology can be regarded as a special case of more general problem of preventing the transport of matter towards a certain target. For instance, many electronic devices based on organic compounds, such as OLEDs and organic solar cells, deteriorate rapidly in air due to reaction with oxygen and water vapour. Likewise, air exposure will cause food to alter its taste, colour and/or texture. A common solution for this type of problem is to use a barrier layer that limits or blocks the transport of corrosive or oxidative species from the environment to the target. Graphene as well as several other twodimensional materials have excellent impermeability, high mechanical properties, and chemical and thermal stability. While graphene has been proposed as barrier coating for a range of scenarios, graphene-based barrier layers face a number of limitations and challenges that must be considered, depending on the application. In this review, we present a comprehensive overview of these potential roadblocks for graphene-based coatings - and related two-dimensional materials - to aid research in this direction, and promote the development of ubiquitous, cheap and powerful barrier technologies based on such ultrathin materials.

\section{Introduction}

Metals and alloys can undergo a series of spontaneous reactions with the environment that irreversibly alter their chemical and physical properties. Material is lost, colour and appearance change, mechanical properties deteriorate; and eventually these metallic parts cannot function anymore. At best, they need to be replaced, which is very costly and time consuming. In the worst case, material degradation causes damage to humans, animals, property or to the environment. This process of gradual degradation of metals and alloys by chemical or electrochemical reactions with the environment is known as corrosion.

In a study called the International Measures of Prevention, Application, and Economics of Corrosion Technologies (IMPACT), NACE International, the worldwide corrosion authority with headquarter in Houston (Texas, USA), estimated the global cost of corrosion to be US $\$ 2.5$ trillion, which is equivalent to $3.4 \%$ of the global Gross Domestic Product for 2013 (Gerhardus Koch, 2016). There is obviously great societal and technological interest in developing novel and more efficient solutions and materials that can limit or prevent corrosion, and its detrimental consequences. 
For these reasons, a plethora of approaches for corrosion protection exists, including for instance surface pre-treatment, anticorrosive coatings, cathodic protection, anodic protection and corrosion inhibitors (Cottis, 2010, Revie, 2008, Shreir, 2013). Anticorrosive coatings, in particular, are applied on the surface of items in order to protect them from the environment (Sørensen et al., 2009a). These coatings may be comprised of several layers that each contribute a different functionality. At least one of these is a barrier layer (Twite and Bierwagen, 1998), with the task of separating the metallic part from the external environment. In a broader perspective, the prevention of chemical/electrochemical degradation by barrier coatings is of tremendous importance, not only when it comes to protection of metals and alloys, but for instance for food packaging as well (Nakaya et al., 2015).

When graphene - an atomically thin sheet of carbon atoms arranged in a honeycomb lattice - was first isolated at the University of Manchester in the UK (Novoselov et al., 2004), much of the attention went towards the unique electric properties of this new material. At first, it was far from obvious that graphene could have any relevance for corrosion science; especially because graphene at the time was obtained exclusively through mechanical exfoliation, a low throughput, non-scalable method that delivers graphene flakes less than $0.1 \mathrm{~mm}$ in size. However, the discovery in 2008 (Bunch et al., 2008) that graphene is impermeable to all gas molecules even as small as hydrogen and helium, along with the first demonstrations, in 2009, of the synthesis of large-area graphene on copper foils via chemical vapour deposition (CVD) (Li et al., 2009), fundamentally changed this scenario (Figure 1). With its excellent mechanical properties (Shinohara and Tiwari, 2015), chemical inertness and stability, complete impermeability (Bunch et al., 2008) and the possibility of being produced in large areas from cheap precursors ( $\mathrm{Li}$ et al., 2009), the potential of graphene to be used as a barrier technology has been deemed significant (Böhm, 2014b).
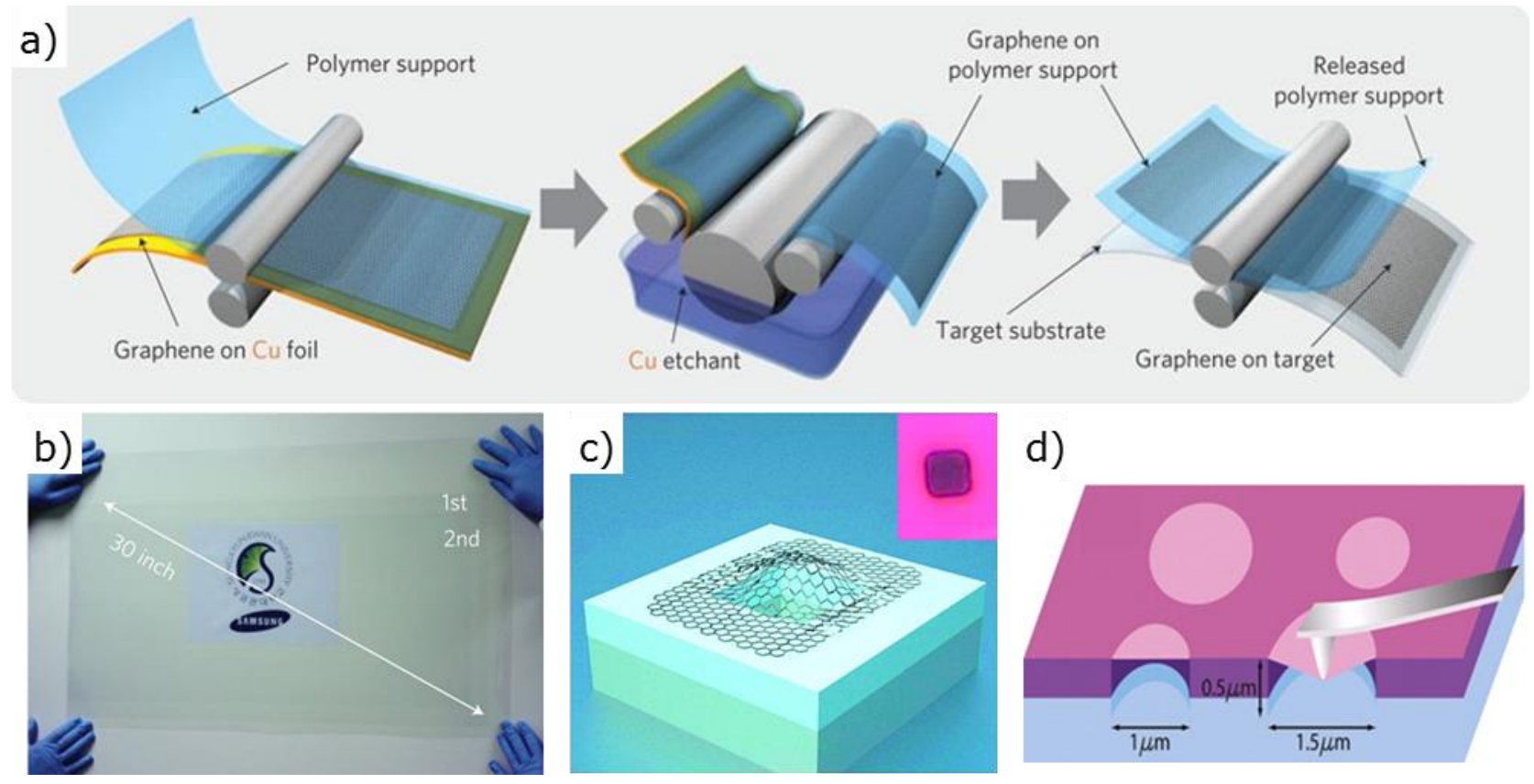

Figure 1. a) Graphene on copper can be transferred to a target substrate through a roll-based transfer system. b) As an example, graphene sheets longer than 30 inches could be transferred on polyethylene terephthalate (PET)) foils. a) and b) are modified from Ref. (Bae et al., 2010). c) Monolayer, defect-free graphene is impermeable to all gases and can be used to effectively seal off a microchamber fabricated in a Si chip. Reprinted from Ref. (Bunch et al., 2008). d) Nanoindentation experiment performed on suspended graphene membrane by means of an atomic force microscope tip. Modified from Ref. (Lee et al., 2008). 
In one of the first reports indicating the corrosion resistant properties of graphene (Sreevatsa et al., 2009), the authors measured the surface potential of steel protected by a p-n junction with or without a graphene layer between the junction and the metal. The interest in graphene playing a role in an anticorrosive coating, however, was ultimately triggered by the seminal paper by Chen et al. (Chen et al., 2011a) that unambiguously demonstrated the ability of a graphene coating to protect metals from reactive environments over relatively short time scales. The authors deposited graphene directly on copper and copper/nickel alloys by chemical vapour deposition and measured the ability of the graphene layer to protect the same substrates. These samples, along with the corresponding bare metal substrates, were either heated in an oven for $4 \mathrm{~h}$ at $200{ }^{\circ} \mathrm{C}$ in laboratory air, or immersed into a solution of $30 \%$ (weight/weight) hydrogen peroxide for $45 \mathrm{~min}$. The graphene-coated samples were observed to be less corroded than their bare counterparts in all tested environments. The authors attributed this difference to the impermeability of graphene, observing that the intimate contact between graphene and the growth catalyst made it difficult for oxidizing and reactive agents like water and oxygen to reach the underlying metal surface. The stability and excellent barrier properties of graphene comprise the main reason for numerous studies of its potential as a corrosion prevention technology.

Although the first research articles on graphene for corrosion technology appeared later than those in other mainstream fields (e.g., transistor, gas sensor and spintronics), the number of citations is growing at a high rate (Figure 2), demonstrating the quickly growing interest of the graphene community for barriers and corrosion protection. Numerous reviews and articles discuss the general use of graphene as corrosion barriers (Böhm, 2014a, Gergely, 2018, Nine et al., 2015a).
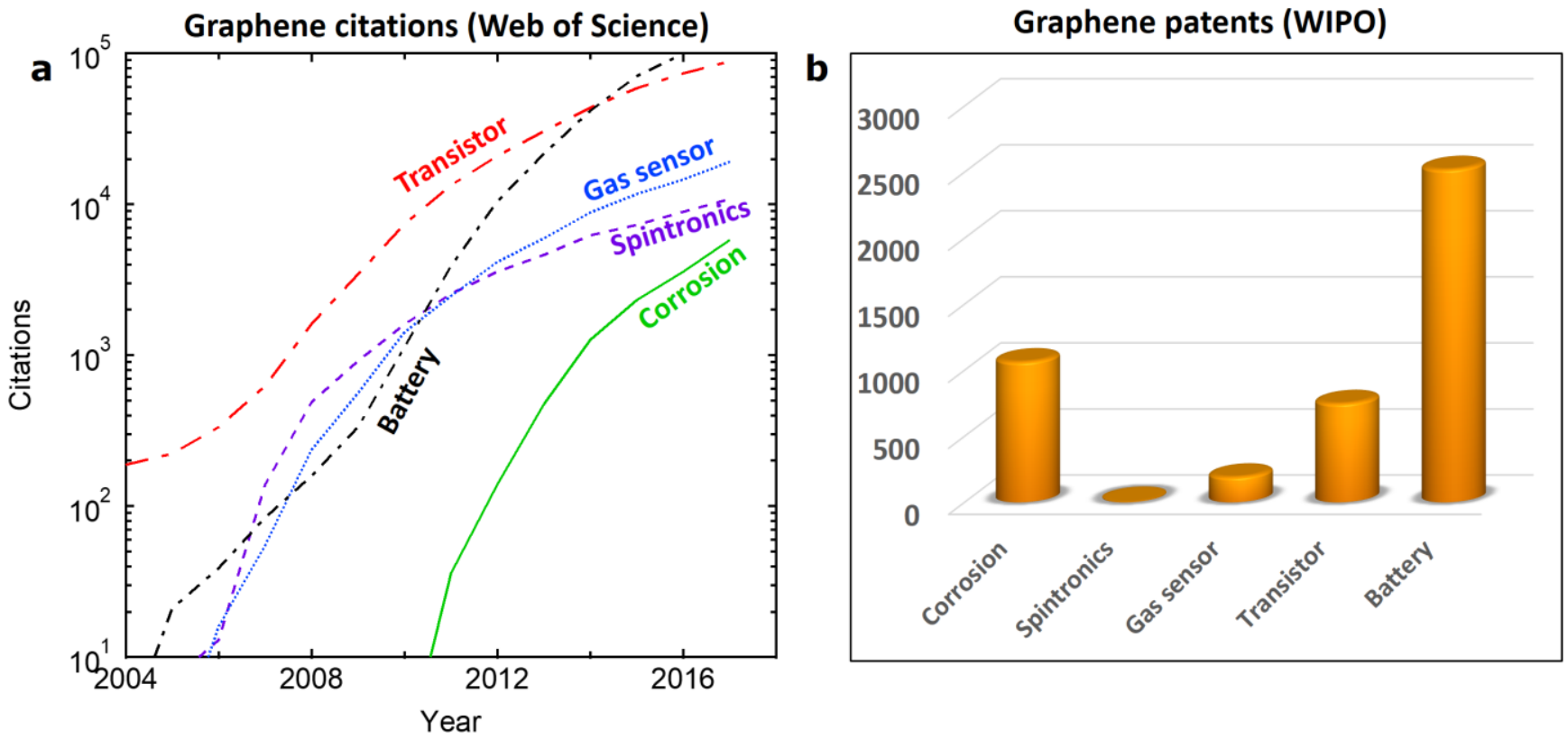

Figure 2. (a) Number of citations of scientific papers dealing with graphene in four different research fields: corrosion, spintronics, gas sensor and transistor. Source: ISI Web of Knowledge.(b) Number of patents with search pattern: "graphene AND corrosion" etc. Source: WIPO (World Intellectual Property Organisation).

In this topical review, we focus on the technological and scientific challenges associated with the use of continuous 2D materials (thin films) as barrier coatings for corrosion protection of metals and alloys. The review focuses primarily on graphene and hexagonal boron nitride $(\mathrm{hBN})$. We target researchers in 
academic and industrial environments, working on or interested in barrier coatings based on twodimensional materials. The purpose is to point out the pitfalls, roadblocks and opportunities garnered ours and others research in the topic, as well as to point to areas that are in need of more systematic investigation for graphene barriers to realise their technological potential.

Anticorrosive coatings based on materials derived from bulk graphene, such as graphene oxide, reduced graphene oxide, colloidal graphene (or colloidal hBN) and fluorographene, are not considered here since previous works have already reviewed some of these systems (Yoo et al., 2014, Nine et al., 2015b).

The challenges that 2D material-based coatings must face are divided into three categories (Figure 3);

- Challenges related to the deposition of such coatings on realistic substrates either directly by synthesis or by transfer from a remote catalytic substrate. These challenges specifically involve direct growth on alloys; and growth/transfer on large, curved or rough surfaces.

- Phenomena that induce failure of such ultra-thin coatings - for instance, poor adhesion and delamination, galvanic corrosion, damage induced by wear and friction.

- Challenges related to the upscaling that 2D material-based coatings face on the path from laboratory to industry. 


\section{Fabrication challenges}

Low temperature growth

on sensitive alloys

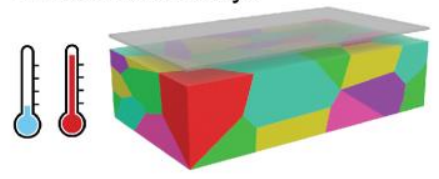

Rough and non-uniform surfaces

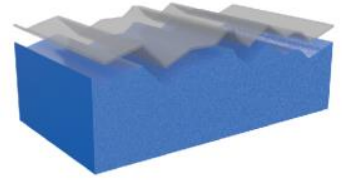

Growth or transfer to large sizes and curved surfaces

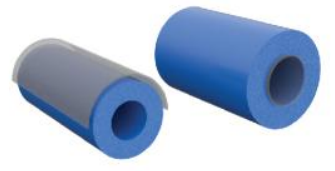

Layered/hybrid architectures

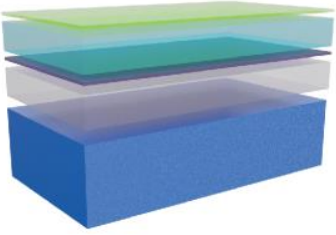

\section{Failure challenges}

Defects, grain boundaries and wrinkles

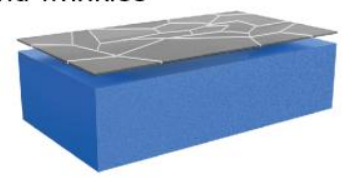

Galvanic corrosion

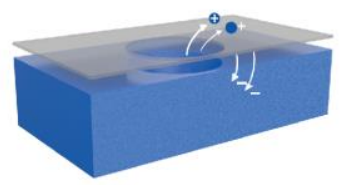

Adhesion/delamination/intercalation

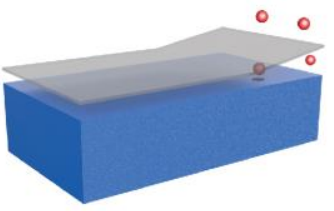

Friction/wear/tribocorrosion

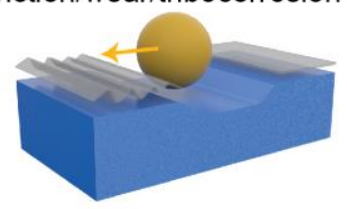

\section{Application challenges}

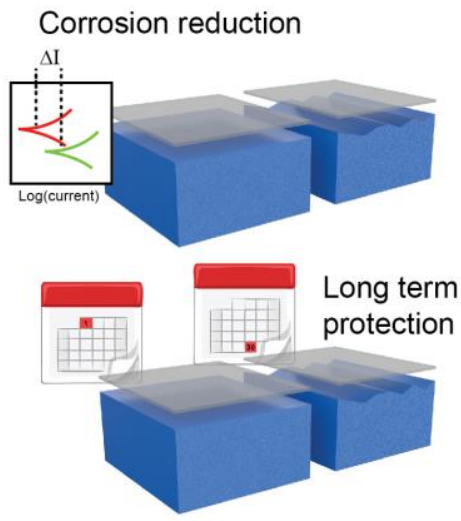

Harsh environments (temperature, chemistry, multiphase)

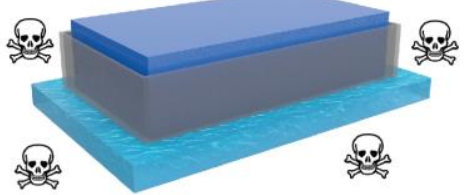

Cost and TRL

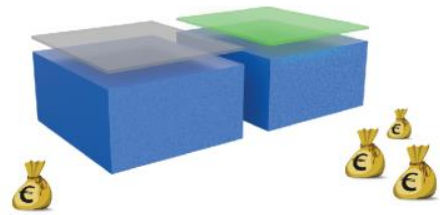

Figure 3. Overview of the challenges that 2D material-based coatings face. We have grouped these challenges into three categories, namely fabrication, failure and application challenges. These will be further discussed in the text.

\section{Fabrication}

\subsection{Direct synthesis on target metals}

The most straightforward way to cover a metal subject with a graphene-based coating is simply to synthesise the graphene film directly on its surface. Since the report by Li et al. (Li et al., 2009), chemical vapor deposition (CVD) has become by far the most used technique for the growth of high quality graphene on large areas (Singh et al., 2011, Deng et al., Lin et al., 2018). The CVD technologies available today make it possible to grow uniform graphene sheets of high quality on wafer-scale (Tao et al., 2012, Luo et al., 2011, Lee et al., 2014) . In short, the exposure of a hot metal surface to a hydrocarbon gas for a time-span ranging from minutes to hours leads to the formation of a continuous graphene film on the surface. In fact, any carbon-containing gas, vapour precursors or even solid may be used (Ruan et al., 2011). The metals most commonly used are copper and nickel, with typical growth temperatures around 800-1050 ${ }^{\circ} \mathrm{C}$ (Zhang et al., 2013c, Muñoz and Gómez - Aleixandre, 2013). In 
general, higher temperatures lead to higher structural quality of the synthesized graphene sheet, at the cost of increased catalyst evaporation.

While the necessity for high temperatures adds to the cost and environmental footprint of many applications of graphene due to the high energy consumption, it is particularly problematic when it comes to using graphene as a protective coating for alloys. Alloys such as steels are irreplaceable in many industries and application - from maritime to offshore, from chemical and oil to construction and transport industry - and generally do not withstand the high temperatures needed for high quality graphene synthesis via CVD process. These alloys may for instance undergo thermally induced segregation when heated for prolonged times, which subsequently leads to unwanted alteration of their microstructure and ultimately physical properties essential for their performance (Chen et al., 2011b, Blesman et al., 2015, Hong et al., 2015, Zhang et al., 2013a). Few works have addressed the lowtemperature growth of high quality graphene on pure metals, like copper or nickel. With hydrocarbon precursors, plasma-enhanced CVD graphene films can be grown at temperatures in the range of $300-$ $400{ }^{\circ} \mathrm{C}$. Raman spectroscopy, however, showed that the films were of quite low quality (Kim et al., 2011a). One approach towards improving the quality is to modify the catalytic properties of the substrate. For instance, using an $\mathrm{Au}-\mathrm{Ni}$ alloy instead of pure Ni enables the growth of graphene of reasonable graphitic quality at temperatures as low as $450{ }^{\circ} \mathrm{C}$, as assessed by Raman spectroscopy (Weatherup et al., 2011). This approach, however, is generally not practical for alloys such as steel, as the addition of another metal to the alloy is likely to change the mechanical and chemical properties of the alloy, as well as increasing production costs. Sun et al. (Sun et al., 2010) lowered the growth temperature from $1000{ }^{\circ} \mathrm{C}$ to $800{ }^{\circ} \mathrm{C}$ by using solid precursors instead of the standard hydrocarbon gases.

In any case, such temperatures are still too high for all commonly used alloys. More recently, Li et al. showed that if liquid precursors such as benzene are used, high quality monolayer graphene flakes can be synthesized at temperature as low as $300{ }^{\circ} \mathrm{C}$ (Li et al., 2011). Benzene consists of six carbon atoms in a ring, which in this case plays the role of a primary building block for graphene. Benzene molecules need only dehydrogenate and connect to each other in order to form larger graphene sheets. Since this synthesis process does not involve the breaking of C-C bonds, the assembly of the honeycomb lattice can take place at much lower temperatures. Nevertheless, the authors still used a pre-growth substrate annealing of $1000{ }^{\circ} \mathrm{C}$, and hence the proposed approach is still not free of high-temperature steps.

Wu et al. used a two-step approach to lower the temperature growth to $300{ }^{\circ} \mathrm{C}(\mathrm{Wu}$ et al., 2013). They made use of naphthalene as a solid precursor, after first depositing a film of coronene - a sevenbenzene-ring molecule - on the copper substrate. In this approach, the authors propose that coronene molecules on the copper surface serve as seeds by providing preferred nucleation sites to which the absorbed naphthalene molecules can attach more easily, eventually creating larger graphene domains. In this way multiple nucleation is suppressed, which was observed to have a positive impact on the quality of the resulting graphene sheet.

Following a similar approach, we recently demonstrated that graphene-like coatings can be synthesized on industrial-grade Inconel surfaces from a molecular coronene precursor at a temperatures of $350{ }^{\circ} \mathrm{C}$ (Figure 4) (Jon Iversen, 2018). The result is a multilayer coating consisting of inter-stitched $\mu$ m-sized graphene crystals exhibiting a strong $\mathrm{sp}^{2}$ component, as observed by X-ray photoelectron spectroscopy (XPS) measurements. The corrosion performance of the graphene-coated Inconel samples was compared to uncoated samples, and was assessed by polarization curve measurements, also termed potentiodynamic scans, PDS, under immersion in $5 \mathrm{wt} \% \mathrm{HCl}$. A Tafel analysis was performed to extract 
values of the corrosion rate. Our graphene coating on the Inconel substrate was observed to reduce corrosion rates from $170 \mu \mathrm{m} /$ year for the uncoated samples to $0.3 \mu \mathrm{m} /$ year for the coated areas, with little change between the values for samples exposed to $5 \mathrm{wt} \% \mathrm{HCl}$ for 1 or 40 days (Jon Iversen, 2018)

While PDS is widely used for evaluating the performance of 2D material-based coatings (Prasai et al., 2012, Singh Raman et al., 2012, Aneja et al., 2015, Sahu et al., 2013, Huh et al., 2014, Husain et al., 2013), we want to point out that the results of PDS experiments performed on coated metals should be used with caution. It is not straightforward to evaluate the corrosion rate from PDS measurements via the Tafel extrapolation method for coated systems, since this method assumes activation control (McCafferty, 2005), i.e. that electron transfer is the rate limiting step leading to corrosion. This is not the case for a coated material, where the limiting step is diffusion of reactive species through the coating barrier, with the assumption that reactions do not take place at the barrier. We suggest electrochemical impedance spectroscopy (EIS) in combination with PDS as a more reliable choice to test the effectiveness of graphene coatings. While we included EIS measurements in our study on Inconel, we quote the PDS measurements here to allow the reader compare to other studies, while bearing in mind that this approach has its limitations.

a)

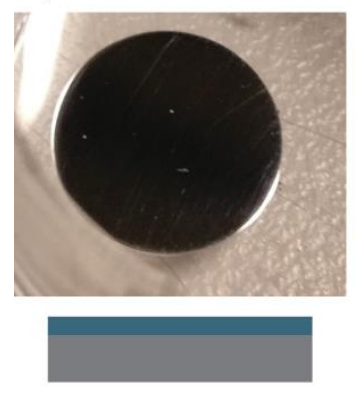

Step 1: Polish a pristine Inconel puck

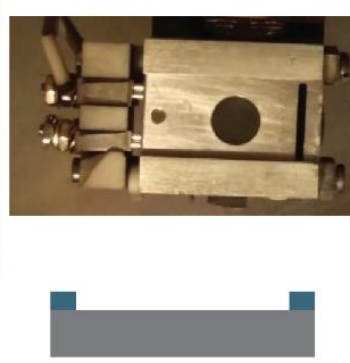

Step 2: Clean the puck in a sample holder to remove the intrinsic oxide layer

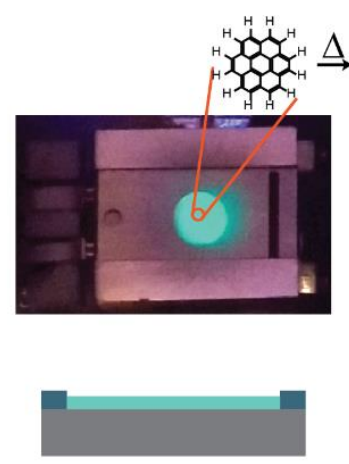

Step 3: Deposit a thick layer of coronene molecules



b)

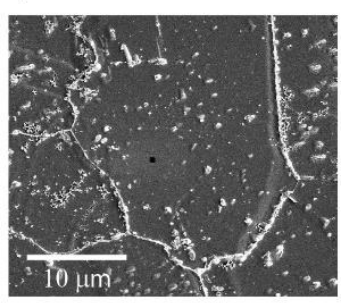

Step 4: Annealing the coronene produces a graphene-like coating

Figure 4. a) Schematic representation of low-temperature graphene growth on an Inconel 625 substrate. b) SEM image of the synthesized coating, demonstrating the continuous domain nature of the graphene-like layer.

\subsection{Transfer onto target metals}

Although direct growth of graphene on Inconel and different types of steel can be achieved using lowtemperature methods, there is not yet any evidence that it will work for other classes of industrially relevant alloys, such as aluminium-based alloys. Aluminium alloys find wide application in the aerospace industry. In this case, growing graphene sheets on a suitable catalyst substrate and then mechanically transferring these onto the target metal substrate could be a viable solution to extend the applicability of CVD graphene for anticorrosive coatings. Prasai et al. (Prasai et al., 2012) demonstrated the use of protective coatings made by transfer of continuous graphene films, and evaluated the corrosion inhibition performance of three sets of samples, (i) copper and (ii) nickel covered by as-grown CVD graphene, and (iii) nickel coated with graphene grown on copper first and then mechanically transferred onto nickel. 


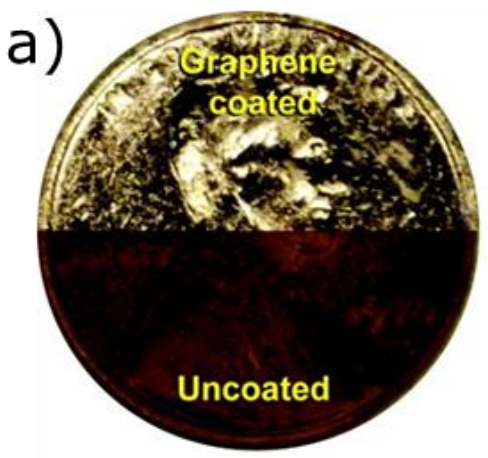

US Penny after $\mathrm{H}_{2} \mathrm{O}_{2}$ Exposure

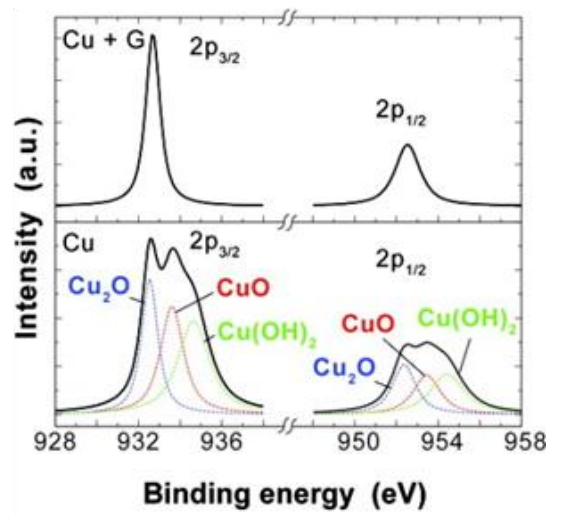

Binding energy $(\mathrm{eV})$

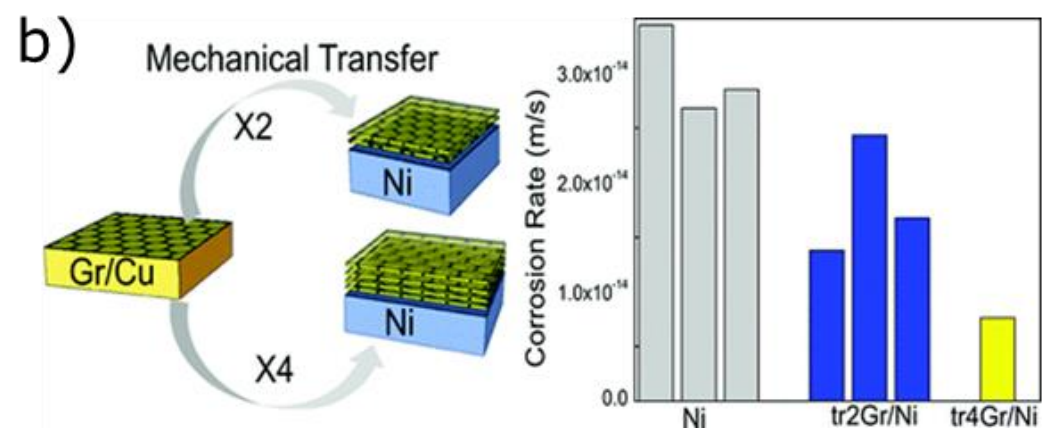

Figure 5. a) Left: A single layer of graphene grown directly on a US penny copper coin can effectively protect it from oxidation when immersed in oxidizing solutions. Optical investigation highlights the difference between the half of the coin that was coated with graphene and the half that was not. Right: X-ray photoemission spectroscopy core-level Cu2p spectrum of coated (upper) and uncoated (lower) copper foil after air anneal $\left(200^{\circ} \mathrm{C}, 4 \mathrm{~h}\right)$. Modified from Ref. (Chen et al., 2011a). b) Left: Single layers of graphene grown on copper can be transferred on nickel to realize multilayer coatings. Right: the corrosion rate for nickel coated by such multilayer coatings is lower than that of bare nickel substrates. Modified from Ref. (Prasai et al., 2012).

The authors found that the corrosion rates of copper and nickel when protected by as-grown graphene were reduced by 7 and 20 times, respectively, if compared to the bare metal counterparts (Figure 5b). On the other hand, when CVD graphene layers are transferred onto nickel, the reduction in corrosion rate was not as effective. This was attributed to tears and rips in the graphene film that may have resulted from the transfer process and provided a passage for corrosive species to diffuse toward the metal surface. Later studies confirmed that graphene coatings grown directly on a metal outperform mechanically transferred graphene (Mišković-Stanković et al., 2014). Besides the damage inflicted to graphene by the mechanical transfer, the problem with transferred graphene coatings is the weak adhesion to the target metal surface, which, over time, causes delamination of the coating (Ye et al., 2015). This is partially due to the intrinsic surface roughness of the target subject; the smoother the surface, the stronger the adhesion with the graphene sheet. This is in contrast to some types of conventional coatings, where surface roughness may be increased by etching or blast cleaning (Hagen et al., 2016) to anchor the coating, increasing contact area and slowing down cathodic delamination (Sørensen et al., 2009b). For chemically inert coatings like graphene that do not spontaneously form chemical bonds with the substrate, a nitric acid treatment of the metal substrate before transfer can make it smoother and thereby improve adhesion between metal and coating (Huang et al., 2017). Strong graphene-metal interaction is essential to achieve effective long-term protection of the metal 
(Weatherup et al., 2015), and even though using transferred graphene could expand the applicability of CVD graphene to a larger range of substrates, poor adhesion still remains a serious roadblock.

The adhesion can be improved by chemical functionalization of graphene that induces bond formation between the substrate and the graphene layer (see Section 3.4) or by the inclusion of a suitable adhesive spacer layer placed between the graphene barrier layer and the target substrate, which we will discuss in the following section.

\subsection{Hybrid coatings}

As mentioned above, an approach to improve the adhesion between a graphene barrier layer and the substrate is to introduce an adhesive polymer between them. In extension of this basic concept, we developed a hybrid polymer-graphene coating architecture (Yu et al., 2018) that improves the adhesion to the substrate, while also addressing several other problematic issues, such as galvanic corrosion (see Section 3.5). The hybrid coating is fabricated by inserting graphene sheets between layers of polymer. Similar polymer-graphene sandwich structures have been previously employed for electromagnetic shielding applications (Batrakov et al., 2014).

In our study, we used a polyvinyl butyral (PVB) coating applied to a commercial aerospace aluminum alloy (AA2024). PVB is often used with AA2024 for corrosion protection, and is commonly quoted as an excellent corrosion protector of diverse metals, with the PVB market expected to reach 4 billion USD by 2024 (source: Grand View Research). We compared the effect of immersion in simulated seawater on uncoated AA2024, AA2024 coated with pure PVB coatings, and AA2024 coated with graphene-PVB hybrid coatings.

Specifically, we observed that the hybrid coating with two graphene layers embedded in a PVB film (i.e., the graphene-PVB hybrid coating) entirely suppressed corrosion of the substrate, showing no change of the surface even after 120 days of immersion. On the other hand, AA2024 coated with a graphene-free polymer coating of the same thickness, and fabricated in the same way, suffered from heavy corrosion after 30 days of immersion (Yu et al., 2018).

Additional electrochemical tests confirmed this result. In Figure 6a, electrochemical impedance spectroscopy data show that while the magnitude of the low frequency impedance $\left(|\mathrm{Z}|_{0.01 \mathrm{~Hz}}\right)$ of a sample coated with graphene-free polymer coating drops by two orders of magnitude after just 30 days of immersion, both of the two-layer graphene hybrid coatings keep a high value of $|Z|_{0.01 \mathrm{~Hz}} \sim 10^{9} \Omega \mathrm{cm}^{2}$, even after 120 days of immersion. This value is five orders of magnitude larger than the value for bare AA2024. PDS measurements showed similar positive impacts of the hybrid coating (Yu et al., 2018) as illustrated in Figure 6b.

Bearing in mind the limits of the PDS technique, the corrosion rate of the sample with graphene-free coating changed from $20 \mathrm{~nm} /$ year after 1 day of immersion, to $300 \mathrm{~nm} /$ year after 30 days of immersion, indicating degradation of the corrosion inhibition performance of this coating. In contrast, the sample coated with the polymer-graphene hybrid had a low corrosion rate below $2 \mathrm{~nm}$ /year both before and after 120 days immersion. This study clearly demonstrates the dramatic improvement to the barrier properties of a polymer coating provided by inclusion of atomically-thin graphene layers (Yu et al., 2018). To the best of our knowledge, this study is also the first reported example of medium/long-term corrosion protection achieved with continuous graphene sheets. Tests on other industrially relevant alloys, like brass and steel, also showed the hybrid coating to provide effective protection against corrosive species. 
Due to the inner polymer layer acting as an adhesive binder between the atomically thin graphene sheet and the metal surface, the hybrid coating approach also allows application of such coating to curved and rough surfaces. With a mechanically stronger carrier foil, this approach could be expanded to cover a much wider range of barrier foil applications, i.e. in food packaging and in preventing gas diffusion in gas containers or in stratospheric balloons, which for the smaller molecules like $\mathrm{H}_{2}$ and $\mathrm{He}$ is a serious challenge.
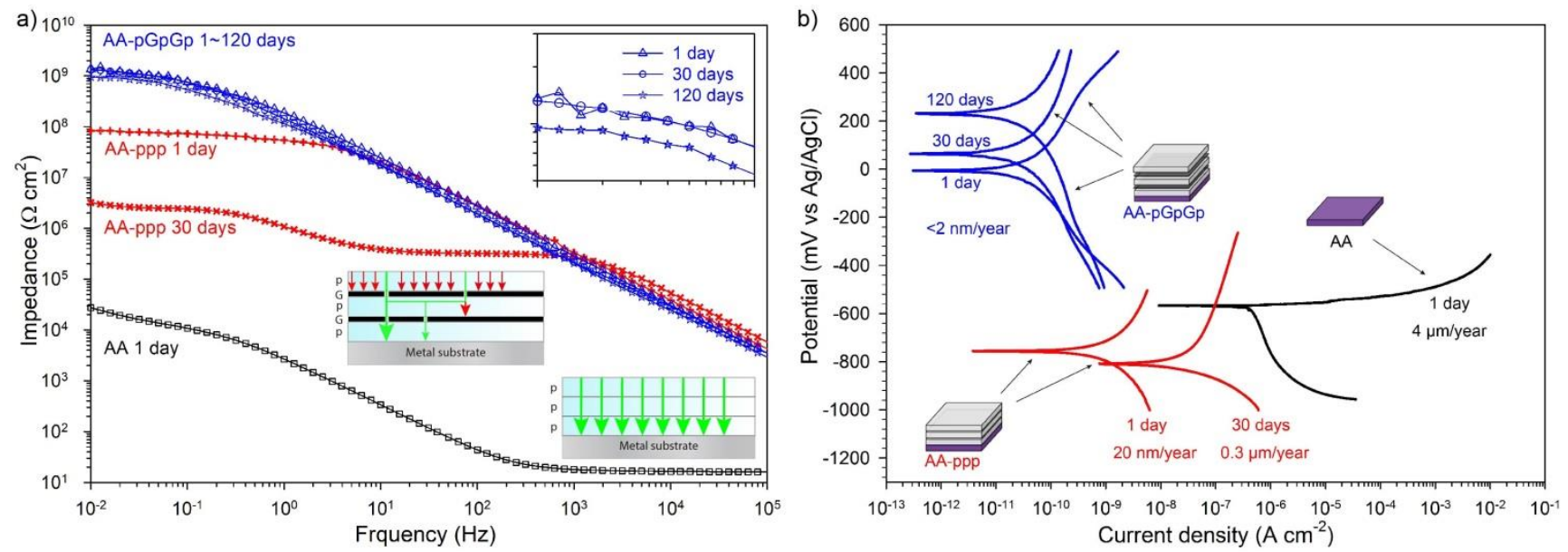

Figure 6 a) EIS results of bare AA after 1 day (black), AA coated by three polymer films (AA-ppp) after 1 day (red +) and 30 days (red X), $A A$ coated by three polymer films and two graphene layers (AA-pGpGp) after 1 day (blue triangle), 30 days (blue circle) and 120 days (blue star) of immersion in $3.5 \% \mathrm{NaCl}$ solution. Inset at top right is a magnified plot of the curves for the $p G p G p$ system at low frequency. Schematic insets illustrating the diffusion pathway of corrosive species in the graphene enhanced coating (pGpGp) and the bare polymer (ppp) coatings are shown. b) Polarization curves of bare AA after 1 day (black), AA-ppp after 1 day and 30 days (red), AA-pGpGp after 1 day, 30 days and 120 days of immersion in 3.5\% NaCl solution. Modified from Ref. (Yu et al., 2018)

\section{Failure modes}

\subsection{Structural defects, grain boundaries and wrinkles}

By being impermeable to any molecule, continuous and defect-free graphene represents the ultimate barrier layer because the substrate is kept indefinitely separated from the corrosive environment; thus, a single continuous layer of graphene in principle should never fail even in the most corrosive conditions. Although the quality of CVD graphene has been continuously improving over the years towards centimetre-size single-crystal graphene domains (Li et al., 2015), it is not defect free.

Grain boundaries formed where graphene crystallites merge can provide pathways that corrosive and oxidizing species can use to pass through a graphene sheet and reach the metal underneath (Chen et al., 2011a, Duong et al., 2012). Wrinkles can form spontaneously during growth, to release stress caused by the differing thermal expansion coefficients (Chae et al., 2009), or by the mechanical stresses involved in the transfer process. Such wrinkles contribute significantly to the degeneration of resistance to oxidation provided by graphene coatings (Zhang et al., 2013b, Zhang et al., 2014a), in particular at high temperatures (Zhang et al., 2014b). Additionally, even in the absence of boundaries or wrinkles, defects tend to be found near nucleation points of every graphene crystallite (Wu et al., 2011). These defects are weak points in the barrier layer, and can trigger oxidation of the underlying copper foil upon annealing in air at high temperature (Luo et al., 2016). Generally, defects are reactive sites; they are also soft 
targets for chemical etching of graphene (Luo et al., 2017) as well as nucleation sites for growth of additional layers (Zhou et al., 2013b).

\subsection{Healing of defects}

A few strategies have been proposed in order to deal with the challenges associated with the presence of defects in coatings made of continuous CVD graphene. For instance, if the intrinsic graphene defects (such as structural defects and grain boundaries) were "healed" or at least passivated, the oxidizing and corrosive species would not be able to pass through the graphene barrier layer and the underlying metal would remain protected. Hsieh et al. (Hsieh et al., 2013) used aluminium oxide deposited via atomic layer deposition to passivate nanometre-sized structural defects of CVD graphene grown on copper. During the deposition, aluminium oxide islands were reported to form selectively on graphene defects, as the defects lower the free energy for nucleation (Figure 7a-d). After such a site-selective passivation step, permeation through graphene was almost completely suppressed and the graphene coating yielded corrosion inhibition efficiency higher than 99\%, comparable to the best reported copper corrosion inhibitors (Hobbins and Roberts, 1983). Nevertheless, further studies are still required, especially to test the long-term performance of such coatings. Furthermore, atomic layer deposition is too costly and cannot be easily scaled up, making it difficult to envision the use of such a strategy at an industrial scale.

\subsection{Multilayer barriers}

Using a coating made of many graphene layers instead of only one or few is another strategy to passivate graphene defects, and to slow down diffusion of corrosive species towards the coated metal surface. As an example, a multilayer graphene coating was used to successfully protect stainless steel in simulated seawater (3.5\% NaCl solution) (Stoot et al., 2015, Pu et al., 2015). In the work by Stoot et al. (Stoot et al., 2015), a $150 \mu$ m-thick nickel film was electroplated on top of stainless steel 304 (SS), with graphene deposited on top via a CVD process. Owing to the high carbon solid solubility at elevated temperatures, nickel favours the growth of multilayer graphene when used as the growth substrate (Zhang et al., 2013c). Taking advantage of this, a continuous graphene coating with a thickness of 25-40 $\mathrm{nm}$ (which corresponds to 75-120 graphene layers) was synthesized on the Ni-electroplated SS substrates. A coated and a reference uncoated sample were both immersed in boiling simulated seawater for 504 hours. In this test, called the Atlas cell test, the sample is mounted such that one half is immersed in the boiling liquid phase, while the other half is exposed to the hot vapour. Additionally, while the front part of the sample is at $100{ }^{\circ} \mathrm{C}$, the backside is exposed to room temperature, which creates a temperature gradient across the system that tests the integrity and adhesion of the coating in several ways. Many polymeric coatings fail during such a test because of either poor barrier or adhesion properties. Water molecules slowly diffuse through the polymer film and eventually condense at the interface between the coating and the metal substrate, thus generating blisters that induce coating delamination. In our study, when comparing the coated and the uncoated samples by optical inspection before and after the Atlas cell test, the coated specimen remained pristine while the uncoated specimen was heavily corroded, with $\mathrm{Ni}$ oxides visible as both green and black deposits, especially on the side exposed to vapour, see Figure 7e-h. These visual findings were confirmed by energy dispersive $\mathrm{x}$-ray spectroscopy (EDS) measurements performed on both samples after the corrosion test. Oxygen was detected in the uncoated sample, whereas it was absent in the coated one. Furthermore, the multilayer graphene coating was not degraded by the harsh test as assessed by Raman spectroscopy measurements (Stoot et al., 2015). 

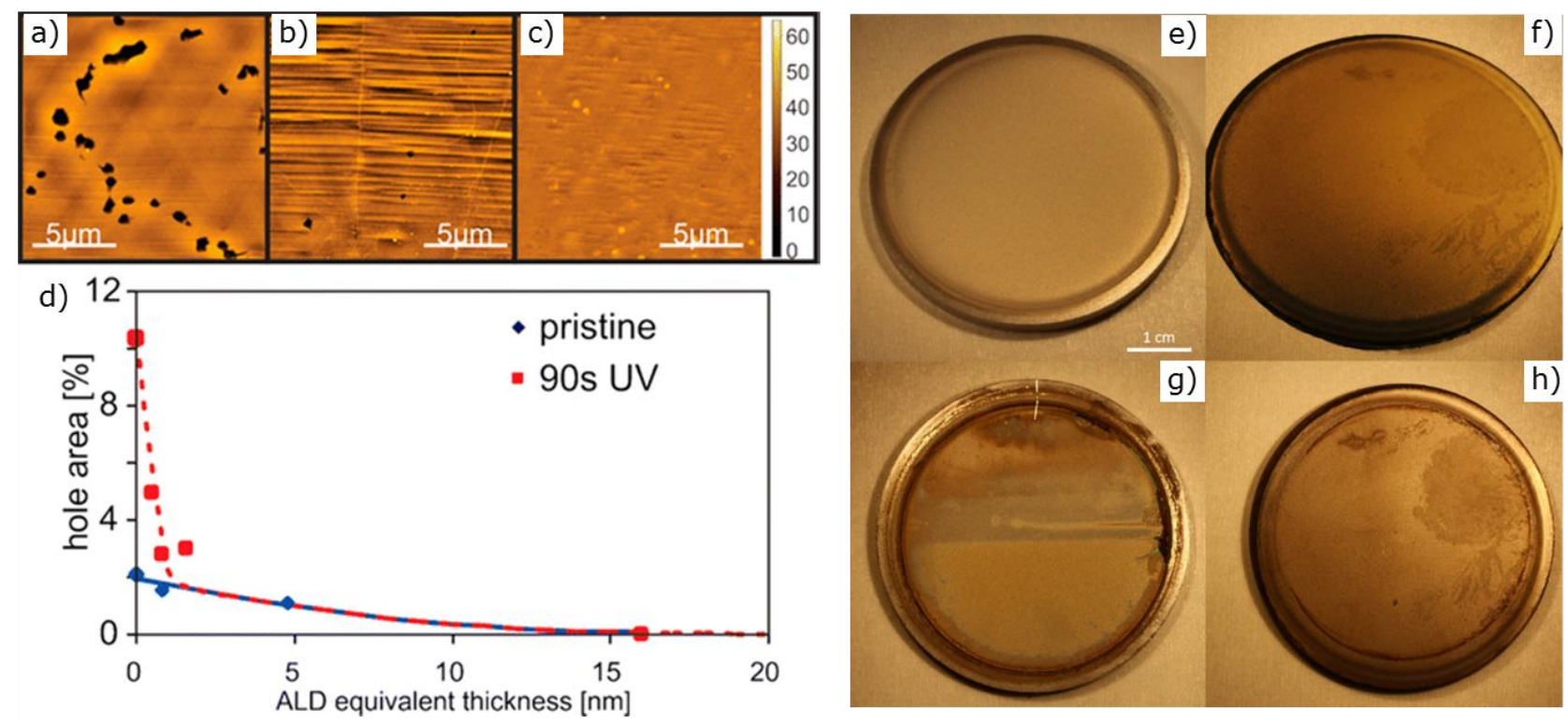

Figure 7. a-d) Atomic force microscope images of etched graphene (a) without, (b) with $5 \mathrm{~nm}$, and (c) with $16 \mathrm{~nm}$ atomic layer deposited alumina film. (d) Copper hole area after deposition of alumina film for pristine and UV-ozone-treated graphene films. From Ref. (Hsieh et al., 2013). e-h) Optical images of stainless steel disks with a nickel seed layer on top. e) and f) show a disk with and without a multilayer graphene coating on top, respectively. $g$ ) and h) display the disks in e) and f) after having been half immersed in boiling simulated seawater. The graphene-uncoated sample is highly corroded, especially in the vapour side (highlighted by the scratch at the edge of the sample) due to the higher oxygen concentration than in the liquid phase. Taken from Ref. (Stoot et al., 2015).

CVD-grown multilayer graphene has also proven effective as an anti-oxidation barrier. Ming and coworkers used multilayer graphene to protect nickel foils from oxidation in simulated primary water of pressurized water reactors (Ming et al., 2014). Nickel is one of the main components of the alloys used to make tubes in steam generators in such reactors. Any oxide film formed on the surface of such alloys is detrimental as it can (i) decrease the heat transfer efficiency of the tube, which correspondingly increases the management cost of nuclear power plants, and (ii) lead to the formation and propagation of cracks, endangering mechanical stability. Ming et al. showed that the multilayer graphene-coated nickel foil showed no obvious sign of oxidation after immersion for $1000 \mathrm{~h}$. Moreover, the test did not alter the structural quality of the graphene film, as assessed by Raman spectroscopy (Ming et al., 2014).

In a recent report, density functional theory (DFT) calculations was used to explain the superior barrier properties of multilayer graphene in comparison with single layer (Zhang et al., 2018). Two different scenarios were considered; one where defects in the individual graphene layers overlap with each other, and one where they do not. In the first scenario, the overlapping defects form a steric hindrance that suppresses oxygen diffusion in the vertical direction, whereas in the second scenario the potential energy barrier for interlayer diffusion is sufficiently high to cause oxygen diffusion in the horizontal direction to become the limiting step.

In the case of impermeable multilayer graphene coatings grown directly on nickel by means of CVD, it seems that under certain environmental conditions, the coating would fail dramatically even over relatively short time scale. Being impermeable to all molecules, and chemically stable at room temperature, graphene barriers are expected to protect metal substrates even in corrosive environments that are harsher than simulated seawater, for instance acids. However, we have recently suggested otherwise. When we placed a droplet of $0.5 \mathrm{M} \mathrm{HCl}$ on top of a multilayer graphene-coated nickel foil, after 5 minutes we observed blisters of 10-20 $\mu \mathrm{m}$ in diameter developing between the coating and the nickel surface (Yu et al., 2016). These small blisters increased in size over time and merged with each 
other. After two hours, blisters with diameters of hundreds of micron were present on the surface. The process continued until the multilayer graphene coating completely delaminated from the nickel foil. We observed such behavior also with other acids, such as $\mathrm{H}_{2} \mathrm{SO}_{4}$ and $\mathrm{HNO}_{3}$, at the same concentration. We proposed these blisters to be hydrogen bubbles (Agmon, 1995). Owing to the low pH environment (i.e. $\mathrm{pH}=0.3$ for $0.5 \mathrm{M} \mathrm{HCl}$ ), protons in the acid solution reaching the nickel surface would lead to spontaneous hydrogen evolution (Pourbaix and Staehle, 1973), according to the reaction:

$2 \mathrm{H}_{3} \mathrm{O}^{+}+2 \mathrm{e}^{-} \rightarrow \mathrm{H}_{2}+2 \mathrm{H}_{2} \mathrm{O}$.

In particular, since wrinkles can run through the whole coating (Chae et al., 2009), from the top to the bottom graphene layer, and are likely to contain a number of defects due to their curvature, we considered the possibility of acid leaking through in such regions, hence reaching the Ni surface (Yivlialin et al., 2018). Although grain boundaries in different graphene layers do not necessarily overlap, they cannot be excluded (Hong et al., 2014, Ambrosi et al., 2013).

Moreover, the fast formation of hydrogen bubbles could also be partially explained in light of recent DFT calculations showing that the hydrogen evolution reaction (HER) rate of graphene-coated nickel is significantly higher than that of bare nickel, and comparable to that of platinum (Zhou et al., 2016).

In this scenario, the multilayer graphene coating prevents as-formed hydrogen from escaping the coating fast enough. The continuously generated hydrogen creates bubbles under the coating that are prevented from deflation because the few defective areas within the graphene film are fully or partially clogged by the liquid media, eventually causing mechanical damage or even delamination of the graphene as was observed experimentally.

\subsection{Intercalation}

In sections 3.2 and 3.3 means to reduce the diffusion rate of reactive species through defects in a graphene-based barrier layer were discussed. Intercalation relates to the migration of species at the target-graphene interface, once those species reach that interface by diffusion through defects and discontinuities. This section examines the processes that can hinder intercalation.

When a graphene coating is grown directly on a metal, intercalation is often governed by the strength of the graphene-metal interaction combined with the affinity of the protected metal towards the corrosive species. For example, when copper is the growth substrate, water and oxygen can intercalate over time (Kidambi et al., 2013). We have investigated the intercalation properties of several gaseous species beneath graphene coatings grown via CVD on $\mathrm{Pt}(100)$. The experiments showed that the coating offered protection against intercalation of $\mathrm{O}_{2}$ (Figure $8 \mathrm{a}-\mathrm{c}$ ), $\mathrm{H}_{2} \mathrm{~S}$, air (tested up to 6 months at room temperature), water (tested up to $75 \mathrm{~min}$ at $60{ }^{\circ} \mathrm{C}$ ) and salt water (tested up to $75 \mathrm{~min}$ at room temperature) (Nilsson et al., 2012, Nilsson et al., 2013, Kyhl et al., 2015). For Pt and Ni substrates intercalation seems not to take place at all for water or oxygen (Nilsson et al., 2012, Weatherup et al., 2015).

However, intercalation beneath graphene on $\mathrm{Pt}$ was observed for $\mathrm{CO}$ at pressures above $10^{-6} \mathrm{mbar}$ (Nilsson et al., 2012), for sequential $\mathrm{O}_{2} / \mathrm{H}_{2} \mathrm{~S}$ exposure (Nilsson et al., 2013), and for salt water at $60{ }^{\circ} \mathrm{C}$ (Kyhl et al., 2015). In the case of hot saltwater, a degradation of the graphene layer itself was also observed in parallel with enhanced intercalation (Figure 8d). In the case of $\mathrm{CO}$, and in the case of sequential $\mathrm{O}_{2}$ and $\mathrm{H}_{2} \mathrm{~S}$ exposure, the graphene layer remained intact, while the reactant species 
intercalated at the graphene-metal interface. In the particular case of $\mathrm{CO}$, intercalation was reported to occur as soon as the differential pressure of $\mathrm{CO}$ was sufficiently high to allow the formation of a high density CO adsorbent phase on the platinum substrate (Longwitz et al., 2004).

a) clean Pt surface

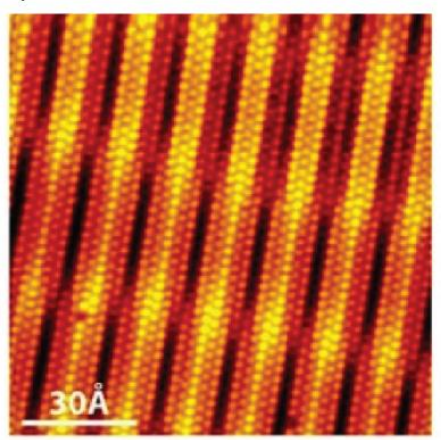

b) graphene coated Pt surface

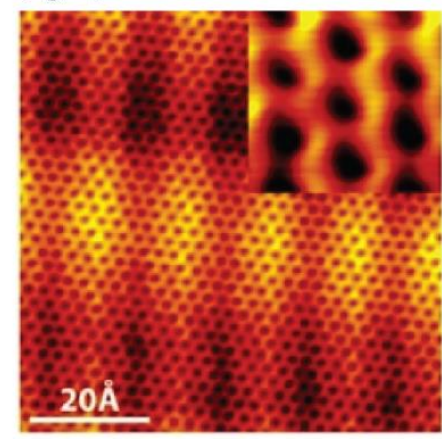

c) $\mathrm{O}_{2}$ exposed surface

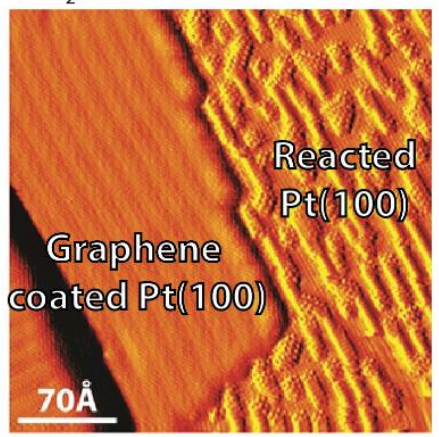

\section{d) Raman spectra}

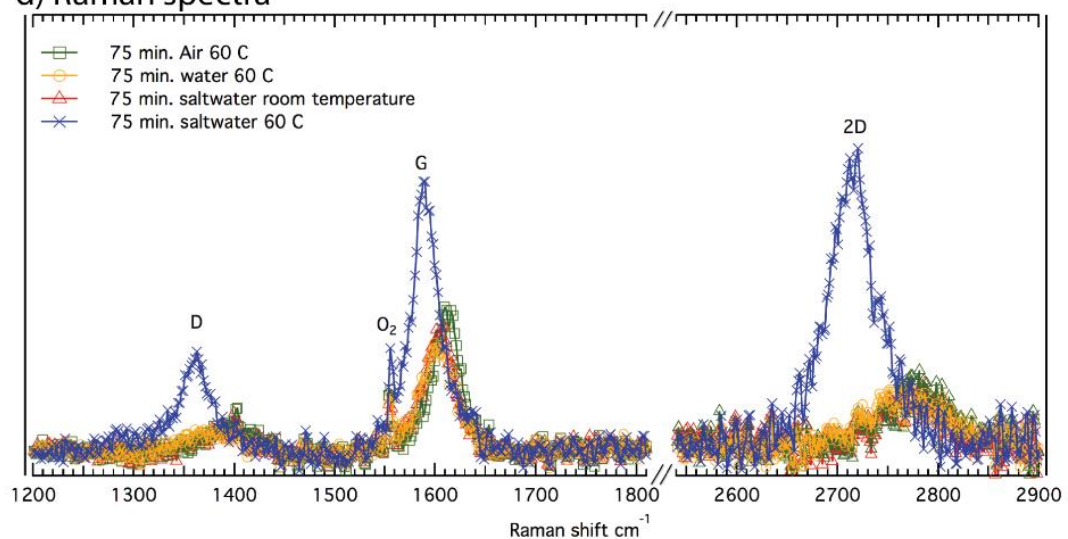

Figure 8. a) Atomic resolution STM image, showing the linear pattern characteristic of a clean reconstructed Pt(100) surface. b) STM image of a graphene covered Pt(100) surface, with both the linear pattern from the clean Pt surface and the hexagonal pattern from the graphene lattice visible. The inset highlights the graphene hexagonal lattice. c) STM image of a Pt(100) surface, partly covered with graphene and then exposed to $\mathrm{O}_{2}$. The graphene covered part of the surface retains the linear pattern characteristic of unreacted Pt(100) while the uncovered part of the surface has reacted to produce an erratic island-like pattern. Modified from ref 61. $d)$ A series of Raman spectra recorded on graphene covered Pt(100) surfaces exposed to a range of corroding environments. Only the system exposed to hot saltwater produces any change in the characteristic graphene spectrum. This shift indicates that the graphene coating has been compromised and the underlying Pt metal has reacted with the environment. Modified from ref 63.

Similar complexity is observed in a number of other graphene-metal systems. On graphene-coated $\operatorname{Ir}(111)$, oxygen intercalation is a thermally activated process that occurs with increasing efficiency at elevated temperatures (Grånäs et al., 2012, Larciprete et al., 2012). Just like for graphene on Pt, CO intercalation in the graphene/Ir system is pressure-dependent and requires pressures in the mbar regime for intercalation to occur at room temperature (Grånäs et al., 2013).

In general, intercalation at a graphene-metal interface depends in a non-trivial manner on the graphenemetal interaction, the chemical nature of any defect sites, the partial pressure and chemical composition of the intercalating gas, the temperature.

One approach to address the problem of weak graphene-metal adhesion is chemical functionalization of the graphene layer. This approach can lead to strong binding between graphene and the underlying metal and we have studied the graphene/Ir(111) system in detail. Experiments show that hydrogen functionalization of graphene/Ir(111) leads to the formation of covalent bonds between carbon atoms in the graphene overlayer and Ir atoms in the substrate. The formation of these bonds is observed to 
prevent $\mathrm{CO}$ intercalation at the graphene-Ir interface at pressures where this process would normally be active. This is schematically illustrated in Figure 9 (Kyhl et al., 2018).

a)

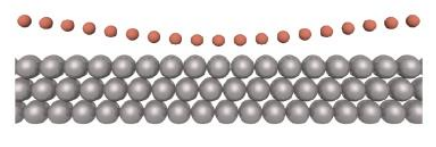

I
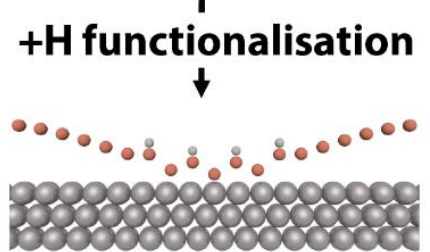
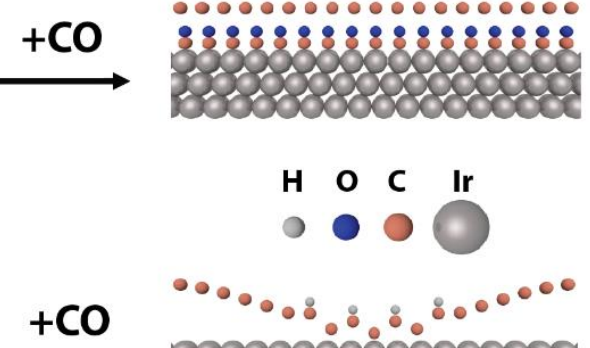

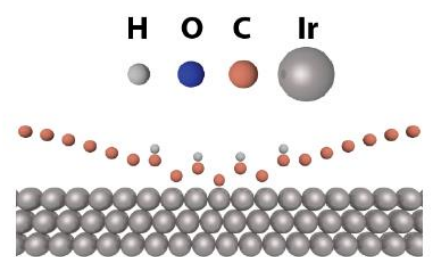

b)

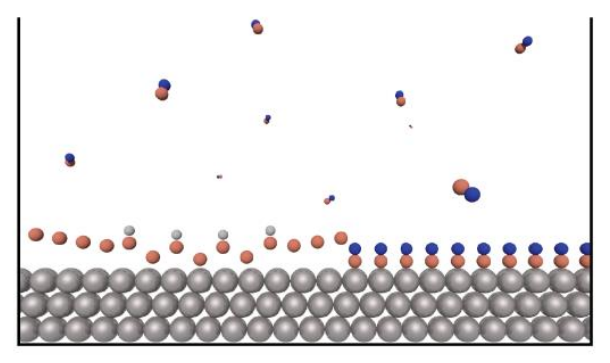

Figure 9. Schematics illustrating the resistance to CO intercalation beneath a graphene layer when the graphene sheet is chemically functionalised with $H$ from the top side. a) 1 mbar partial pressure of CO intercalates between a pristine graphene layer and an Ir substrate (top). Functionalising the top side of the graphene sheet with $H$ simultaneously introduces new $C$-Ir bonds at the backside of the graphene sheet and these new bonds prevent $C O$ molecules from intercalating (bottom). $b$ ) Upon exposure to a background pressure of $\mathrm{CO}$, while $\mathrm{CO}$ molecules adsorb on bare Ir, those same molecules are prevented from diffusing beneath the graphene sheet by the $H$ functionalisation scheme that tethers the graphene sheet to the Ir surface.

\subsection{Galvanic corrosion}

\subsubsection{Galvanic corrosion with graphene barrier layers}

Initial studies on graphene coatings highlighted structural defects in the coating, and more precisely molecular diffusion through these defects, as the main obstacles toward the use of graphene as an anticorrosion barrier. The verdict was that a graphene coating would somewhat inhibit corrosion of the underlying metal surface provided the defect density in the graphene layer could be limited (Chen et al., 2011a, Prasai et al., 2012, Kirkland et al., 2012).

In 2013, however, two independent studies carried out by Schriver et al. (Schriver et al., 2013) and Zhou et al. (Zhou et al., 2013a) pointed out another mechanism, which despite being well-known in corrosion science, had been overlooked in the context of graphene-based barrier coatings. The authors demonstrated that over long time scales graphene coatings in fact promote and accelerate corrosion of the underlying metal substrate. Both studies systematically compared the oxidation of bare copper and copper coated with a CVD-grown graphene monolayer, under several conditions. Schriver and coworkers exposed samples to air at (i) temperatures of $250{ }^{\circ} \mathrm{C}$ and $185^{\circ} \mathrm{C}$ for short (less than $1 \mathrm{~h}$ ) to moderate (up to $17 \mathrm{~h}$ ) time scales, and (ii) ambient temperature over much longer (up to 2 years) time scales. At $250{ }^{\circ} \mathrm{C}\left(185^{\circ} \mathrm{C}\right)$, the bare copper sample immediately started to oxidize, while the graphenecoated sample remained almost unchanged for the first $6 \mathrm{~min}(15 \mathrm{~min})$. The authors explained that within this time-frame, diffusion of $\mathrm{H}_{2} \mathrm{O}$ and $\mathrm{O}_{2}$ towards the metal surface was successfully slowed down by the presence of the graphene barrier layer. These findings indeed confirmed the short-term ability of a graphene coating to inhibit metal corrosion. However, after $17 \mathrm{~h}$, both graphene coated and uncoated samples looked indistinguishable, with the copper surface heavily oxidized in both cases. It was observed that the strain induced by a thick $\mathrm{CuO}$ layer that had grown on the underlying $\mathrm{Cu}$, led to crack formation in the substrate. An even more remarkable difference in the behaviour of bare copper and graphene-coated copper was observed when the samples were kept at room temperature. The bare copper sample displayed minor colour change after 2 years in air, owing to the development of a protective native oxide layer on its surface. On the other hand, the graphene-coated sample began to 
tarnish after only one month. This initial oxidation occurred only in some copper grains, while others remained protected even after several months, probably as a result of a stronger interaction of graphene with grains of certain crystal orientation (Schriver et al., 2013). Nevertheless, after 18 months, the sample was completely oxidized everywhere, with a film of $\mathrm{Cu}_{2} \mathrm{O}$ covering the copper surface. The oxidation after this time was far more pronounced on graphene-coated copper compared to unprotected copper. As reported in Figure 10a, similar results were also found by Zhou et al. (Zhou et al., 2013a). Both papers concluded that having a graphene coating is worse than having no coating at all in terms of long-term exposure to corrosive or oxidative species. The two studies are in agreement with respect to the proposed mechanism for the graphene-enhanced corrosion. In particular, while the formation of a native oxide on bare $\mathrm{Cu}$ eventually blocks the half-reactions needed to continue the oxidation of the bulk (Keil et al., 2010), the presence of graphene allows electrical contact between sparsely protected regions of $\mathrm{Cu}$ to be maintained. Thus, where graphene is present, charge transfer to the copper bulk is maintained, which allows the full electrochemical reaction to continue unimpeded (Figure 10b). The change in the copper surface topography was also responsible for the increase in the number of defects detected in the "aged" graphene as measured by Raman spectroscopy (Zhou et al., 2013a). Like graphite (Zahran et al., 1996, Sloan and Talbot, 1992, Tucker et al., 1990, Xu et al., 2011), the high nobility of graphene makes it cathodic to most metals (including, for instance, copper, nickel, aluminium, magnesium, iron and steel), and promotes their galvanic corrosion (Oldfield, 1988) when in direct contact with them. Hence, prevention of galvanic corrosion is a major obstacle to be overcome if graphene coatings are to be effective as corrosion inhibitors. Although this phenomenon has been clear to the corrosion community for a long time, the reality of galvanic corrosion with graphene layers took some time to dawn on the $2 \mathrm{D}$ research community, as mentioned above.

\subsubsection{Insulating two-dimensional barrier layers}

Ideally, the galvanic-corrosion problem could be solved with an insulating alternative to graphene; a coating based on such a material would not induce galvanic corrosion when in direct contact with a metal substrate, but would still provide excellent impermeability. In 2013, Zheng Liu et al. (Liu et al., 2013) suggested using another $2 \mathrm{D}$ material, namely $\mathrm{hBN}$, in lieu of graphene. In this section we will summarise research efforts that compare the use of $\mathrm{hBN}$ to graphene as a corrosion preventing barrier layer.

In its bulk form, hBN, is a layered material, that is isostructural and isoelectronic with graphite, with $\mathrm{C}$ atoms replaced by alternating $\mathrm{B}$ and $\mathrm{N}$ atoms. A single layer of $\mathrm{hBN}$, also called "white graphene", is a wide bandgap semiconductor that in practice is electrically insulating (CassaboisG et al., 2016). Firstprinciple calculations show that the permeability of a hBN sheet is comparable to graphene when it comes to diffusion of oxygen molecules (Shen et al., 2016). It has been demonstrated that a coating that consists of a few-layers of $\mathrm{hBN}$ performed better than no coating at all, upon annealing of $\mathrm{Ni}, \mathrm{Cu}$ and stainless steel at temperatures as high as $1100^{\circ} \mathrm{C}\left(500^{\circ} \mathrm{C}\right)(\mathrm{Liu}$ et al., 2013). They even used hBN to coat a film of graphene and demonstrated that graphene could survive at $1,000{ }^{\circ} \mathrm{C}$ in air for $2 \mathrm{~min}$, thus increasing the thermal stability of the graphene layer by almost $500{ }^{\circ} \mathrm{C}$. Not only does the $\mathrm{hBN}$ coating effectively protect the metal substrate without inducing galvanic corrosion, it is also stable to temperatures that are incompatible with graphene coatings in ambient conditions. First-principle studies can explain that hBN has a strong oxidation resistance because the energy barrier to adsorption of molecular oxygen is higher than the desorption energy (Zhao et al., 2012). In this sense, hBN coatings may be preferable to graphene coatings for high temperature applications. Further experimental studies have confirmed the high-temperature stability of mono- and few-layer hBN. For example, Li et al. 
mechanically exfoliated 1 to 4 layers of $\mathrm{hBN}$ onto a $\mathrm{SiO}_{2}$ substrate, and heated the sample in air at temperatures in the range of $400-870{ }^{\circ} \mathrm{C}$ ( $\mathrm{Li}$ et al., 2014a). Their results show that hBN can survive temperatures up to $850{ }^{\circ} \mathrm{C}$, even though oxidation commences in some areas already at $700{ }^{\circ} \mathrm{C}$. Moreover, following experiments using atomic force microscopy, they reported that the oxidation initially takes place along the lines where oxygen chains are chemisorbed, and then proceeds in the direction perpendicular to these lines (Li et al., 2014a).

Shen et al. (Shen et al., 2016) compared the protection performance of anticorrosive coatings made of CVD-grown single layer hBN and CVD graphene on copper foil. First, they used DFT calculations to show that both $\mathrm{hBN}$ and graphene exhibit resistance to $\mathrm{O}_{2}$ permeation, with the energy barrier for $\mathrm{O}_{2}$ diffusion through graphene being slightly higher than that for hBN, possibly due to a more uniform electron distribution in the former. Experimentally, the short-term corrosion inhibition performance was evaluated by immersing the graphene/copper and hBN/copper in $\mathrm{HNO}_{3}$ and then carrying out PDS and EIS experiments. The PDS measurements showed that the corrosion rates of graphene/Cu and $\mathrm{hBN} / \mathrm{Cu}$ were comparable. Similar conclusions were drawn from the EIS data. To test the long-term corrosion inhibition of the two different coatings, the two systems were kept in an ambient environment at room temperature with a relative humidity of around $60 \%$ for 160 days. After the test, only $10 \%$ of the $\mathrm{hBN} / \mathrm{Cu}$ sample exhibited a slight colour change, whereas the graphene/Cu sample was severely degraded. Scanning electron microscopy images showed that the surface morphology of the graphene/Cu specimen was highly inhomogeneous as a result of copper oxide formation. Also the X-ray photoemission spectroscopy (XPS) data, collected after the long-term test on both samples, confirmed the superiority of $\mathrm{hBN}$ coatings compared to graphene coatings in preventing the formation of $\mathrm{Cu}$ oxides. The XPS spectra showed a $\mathrm{Cu}$ (II) content of $1.3 \%$ for the $\mathrm{hBN} / \mathrm{Cu}$ and a value three times higher $(4.3 \%)$ for the graphene/Cu sample. These examples support the notion that while the intrinsic barrier properties of $\mathrm{hBN}$ and graphene are comparable, $\mathrm{hBN}$ is superior to graphene for long-term protection as galvanic corrosion is not an issue.

We have measured the real-time evolution of oxide species in copper samples coated with either graphene or hBN single layers grown by CVD (Galbiati et al., 2017). Two sets of samples were subjected to two different oxidative tests. In the first one, the samples were heated continuously from room temperature to $400{ }^{\circ} \mathrm{C}$ in steps of $50{ }^{\circ} \mathrm{C}$ within a $45 \mathrm{~min}$ period. In the second test, the samples were kept at constant temperature of $50{ }^{\circ} \mathrm{C}$ for $60 \mathrm{~h}$. The first experiment tested the behaviour of the samples upon a short but acute oxidative condition; the second experiment simulates a milder but prolonged oxidation. During both experiments, Raman spectra were continuously collected to follow the evolution of the Raman peaks originating from different copper oxides. Over a short period of time and for temperatures below $250{ }^{\circ} \mathrm{C}$, we observe that both graphene and $\mathrm{hBN}$ films provided adequate protection against oxidation of $\mathrm{Cu}$, with graphene even outperforming $\mathrm{hBN}$, which we attributed to a higher number of defects in the CVD-grown hBN single layer. Graphene failed in the second test, producing a heavily oxidised substrate whereas hBN was a successful coating, see Figure 10c. X-ray photoemission spectroscopy and Auger electron spectroscopy confirmed the results of the real-time Raman investigations.

Hexagonal boron nitride barrier layers have also been used to protect other metals from oxidation, for instance Fe (Caneva et al., 2017). Owing to the strong interfacial interaction between as-grown CVD $\mathrm{hBN}$ single layer and the Fe catalyst, oxygen and water molecules do not intercalate at the coatingsubstrate interface, allowing the metal substrate to remain pristine over almost $40 \mathrm{~h}$. Beyond that period of time, Fe oxidation initiates at defective regions in the hBN film, such as grain boundaries, wrinkles, 
and edges, and slowly spreads across the surface, even in the regions covered by defect-free hBN. Interestingly, it was reported that the oxidized Fe areas recover the pristine metallic state after vacuum annealing at around $600{ }^{\circ} \mathrm{C}$, although this also leads to the creation of defects within the hBN layer due to catalytic etching by the underlying Fe substrate. These findings may have implications for magnetic tunnel junctions, where hBN films could be used to preserve the metallic state of ferromagnetic electrodes during processing under oxidizing environments.

$\mathrm{hBN}$ is more expensive to make than graphene with the synthesis routes known today. The common precursors are much less abundant than precursors for graphene growth, and can be toxic or harmful, for example, ammonia or borazine. Until cheap, robust and effective synthesis routes are developed, $\mathrm{hBN}$ based coatings are not likely to be important in the near future. Nevertheless, owing to its high thermal stability, hBN coatings may still be relevant for certain niche applications involving critical, expensive and environment-sensitive components, such as electrical circuits or sensors.

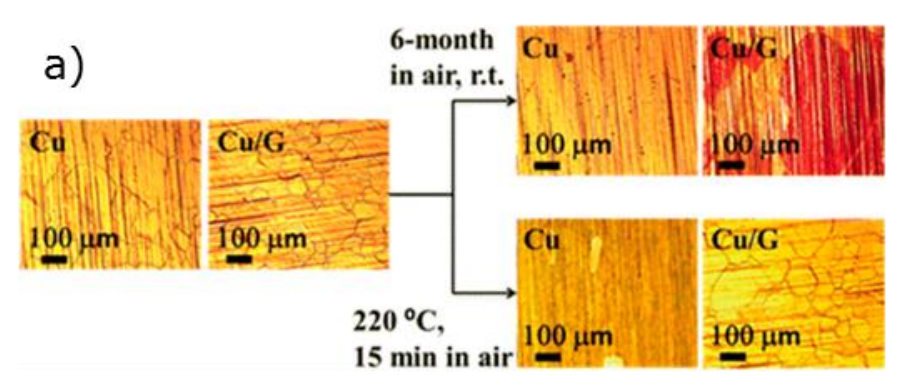

b)

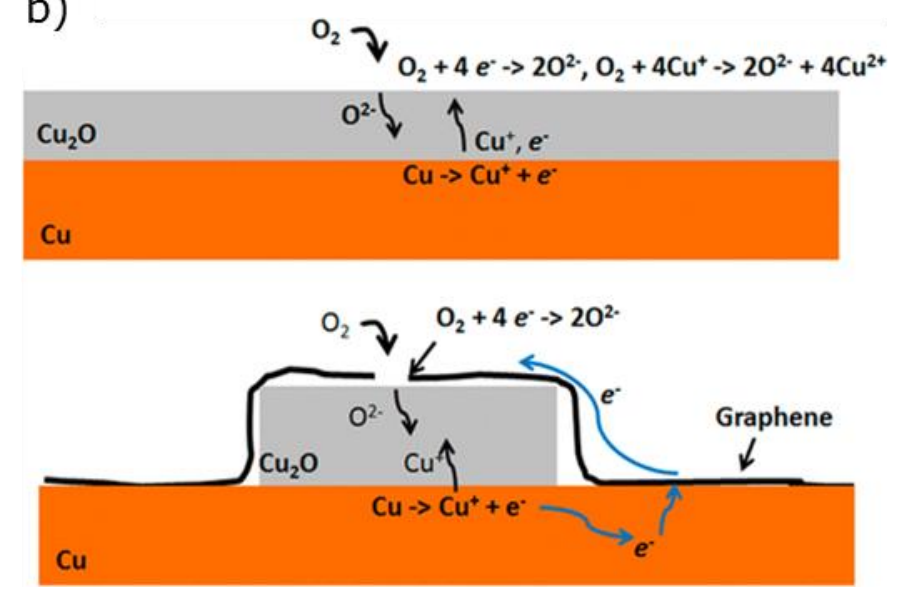

c)

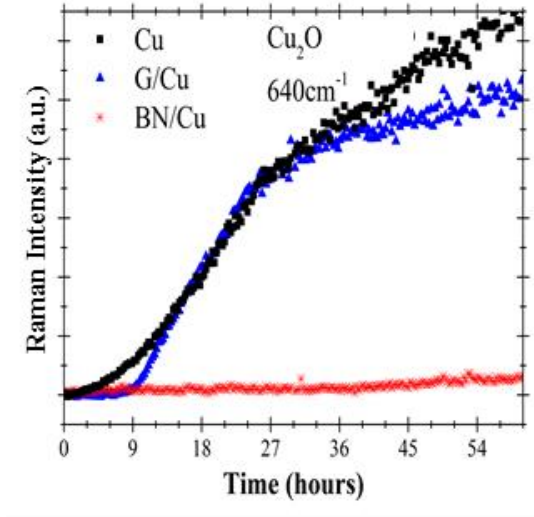

d)

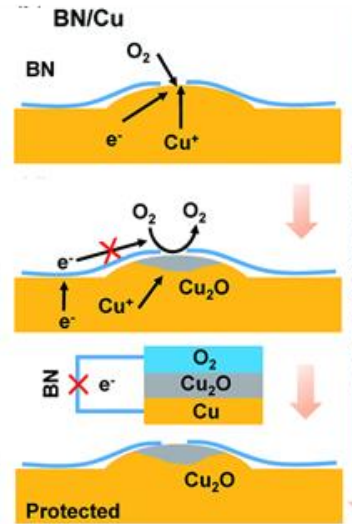

Figure 10. Galvanic corrosion. a) Optical micrographs of bare copper and graphene-coated copper samples after being annealed at 220 ${ }^{\circ} \mathrm{C}$ for 15 min in air, or stored in air at room temperature for six months. b) Illustration of the electrochemical oxidation of copper in the absence (top panel) and presence (bottom panel) of a graphene film. From Ref. (Zhou et al., 2013a). c) Time evolution of the intensity of the Raman signal of $\mathrm{Cu}_{2} \mathrm{O}$ for bare copper, copper coated with graphene and copper coated with hBN upon annealing in air at $50{ }^{\circ} \mathrm{C}$. Taken from Ref. (Galbiati et al., 2017). d) Illustration of the electrochemical oxidation of copper coated with graphene (left column) or hBN (right column) film. From Ref.(Shen et al., 2016), published by The Royal Society of Chemistry.

Another obvious possibility for solving the galvanic corrosion problem associated with graphene barrier coatings is to separate the graphene barrier layer from the metal substrate. If the two materials are not connected, an electrical contact (i.e., a galvanic cell) cannot be established. In this frame, placing an insulating polymer film between graphene and the metal substrate is for instance a way to avoid the formation of the galvanic cell while the same time increasing the adhesion of the graphene coating, as we recently demonstrated (Yu et al., 2018), see also section 2.3. 


\subsection{Friction, wear and tribocorrosion}

Tribocorrosion can be defined as irreversible degradation of a material caused by the combination of wear and corrosion, i.e., a friction-induced damage to the film that introduces specific vulnerabilities to a material beyond those introduced by corrosion alone. Thus, reducing friction and wear between moving mechanical parts is critical to ensure their efficiency and durability.

One of the most common approaches to reduce friction is the use of lubricants. Layered materials like graphite, molybdenum disulphide and even hexagonal boron nitride have long been used for this purpose (Bartz, 1971). It is natural therefore to wonder how thin films or even single layers of such twodimensional materials perform as dry lubricant when applied to a metallic substrate. Although graphene does reduce the friction coefficient of the substrate, it was also found that the frictional behaviour of graphene and graphite are quite different, despite the identical chemical structures. For instance, nanoscale investigations carried out with atomic force microscopy showed that the friction force between the probe and the top layer of graphene decreases with increasing number of graphene layers (Lee et al., 2009b). Further experimental studies confirmed this behaviour, and although several explanations have been suggested (Lee et al., 2009a, Filleter and Bennewitz, 2010, Li et al., 2010, Lee et al., 2010) there is no consensus thus far. Moreover, the static friction force of single layer graphene gradually increases for a few initial atomic periods until a constant value is reached, and that it diminishes with an increasing number of graphene layers. By interpreting experiments performed with atomic force microscopy in relation to theoretical simulations within a molecular dynamics framework, $\mathrm{Li}$ and co-workers (Li et al., 2016) argued that the observed phenomenon is due to the natural tendency for thinner graphene coatings to change configuration. In this picture, AB-stacked multilayer graphene (or graphite) is more rigid and is less likely to respond mechanically to external pressures and forces, which in turn reduces the frictional force (experimental data reported in Figure 11a,b).

Even though the abovementioned studies show that the bulk counterparts seem to provide lower friction than the related single layer structures, it is evident that the latter can still decrease friction of coated substrates. For instance, Kim et al. studied the friction properties at the microscale of graphene grown via $\mathrm{CVD}$ on $\mathrm{Ni}$ and $\mathrm{Cu}$ both before and after transfer onto $\mathrm{SiO}_{2}$ substrates using a home-built microtribometer (Kim et al., 2011b). They also investigated the adhesion of graphene samples at the nanoscale by using a commercial AFM setup. They found that the graphene grown on nickel (i.e. a multilayer film) and transferred onto $\mathrm{SiO}_{2}$ had a coefficient of friction comparable to that of bulk graphite, and lower than that of graphene grown on copper (i.e. a single layer), after transfer to $\mathrm{SiO}_{2}$ (Figure 11c). Regarding the adhesion tests, the authors showed that the pull-off force between the probe and the $\mathrm{SiO}_{2}$ substrate decreased due to the presence of graphene both in the case of the micro-tribometer and AFM measurements. Furthermore, the effect of graphene on the pull-off force was influenced by the material and/or shape of the probe. In particular, when measuring on the same sample, the authors noticed that the pull-off force measured in the micro-tribometer was different for fused silica or a polymeric probe, and different for tips with $50 \mathrm{~nm}$ or $150 \mathrm{~nm}$ radius in the AFM measurements.

Interestingly, Shin and co-workers demonstrated that the friction properties of graphene can be modified by altering the density of defects (Shin et al., 2011). They carried out tests on graphene with or without oxygen plasma treatment. Graphene subjected to oxygen plasma treatment presented a higher number of defects, which resulted in a more intense D peak in Raman spectroscopy. Their results showed that the friction coefficient of pristine graphene is smaller than that of graphene treated with oxygen plasma. This is clearly a disadvantage for the application of graphene as friction-reducing coating. Indeed, if 
during usage, the graphene coating becomes degraded by inclusion of an increased number of structural defects, the friction coefficient is likely to increase.

While there are no detailed studies on the subject of the hBN tribocorrosion as of yet, hBN has been found to provide a lubricating effect with respect to the underlying metal substrate. As shown in Figure $11 \mathrm{~d}$,e, friction force experiments performed with an atomic force microscope showed that monolayer $\mathrm{hBN}$, grown via CVD, reduced the friction force of copper more than 40-fold for a wide range of applied normal forces, and at pressures as high as $46 \mathrm{MPa}$ (Li et al., 2014b).

a)
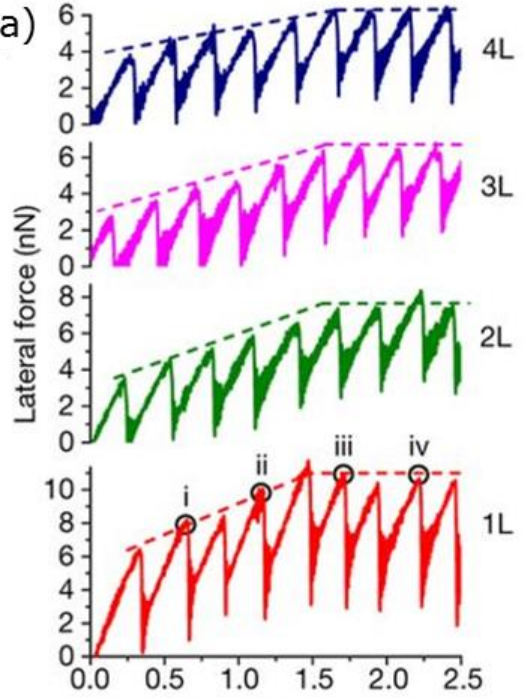

b)

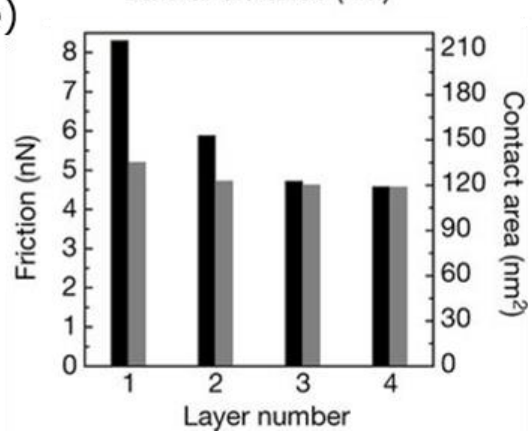

c)

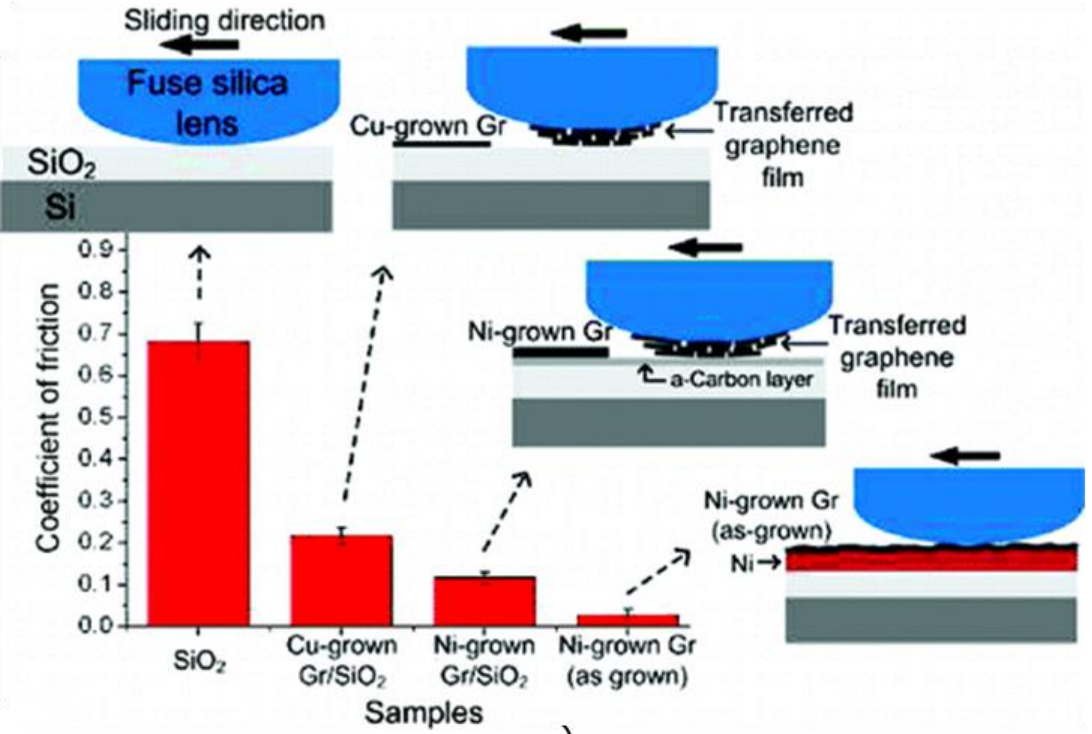

d)

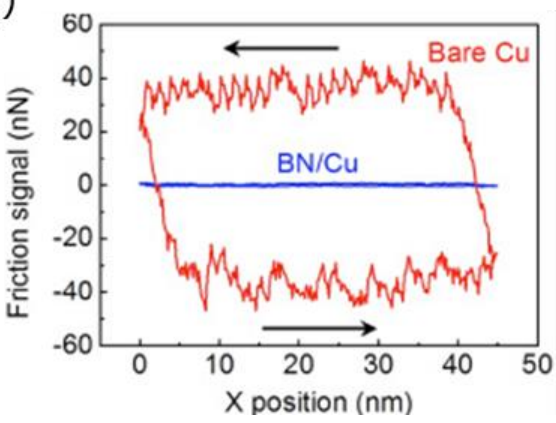

e)

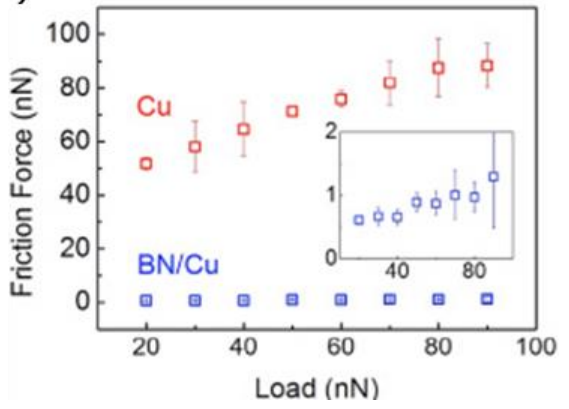

Figure 11. Friction and wear. a) Force traces showing stick-slip behaviour on single (1L) and multilayer (2L-4L) graphene/amorphous-Si substrates, with b) averaged friction force (black) and contact area (grey) as a function of number of layers of graphene. Taken from Ref. (Li et al., 2016). c) Friction coefficients measured for a number of graphene samples. From Ref. (Kim et al., 2011b). d) Friction force signal taken on the bare $\mathrm{Cu}(\mathrm{Cu})$ and $h$-BN-coated $\mathrm{Cu}(\mathrm{BN} / \mathrm{Cu})$ at an applied load of $40 \mathrm{nN}$. e) The deduced friction force as a function of the applied load. From Ref. (Li et al., 2014b).

\section{Commercial challenges}

\subsection{The lab - reality gap}

There is a considerable focus on innovation with respect to graphene barriers for corrosion protection, as indicated by the tens of thousands of patent applications filed so far Source Google Patents; keywords "Graphene corrosion" and "Graphene barrier coating".

However, we would like to stress that the studies reported above were performed in laboratories, with techniques and conditions that are well-suited for fundamental investigations, but less relevant in terms of realistic working conditions. Generally, such investigations alone cannot predict how 2D material- 
based barrier coatings will perform with realistic loads in poorly controlled harsh environments, not to mention on realistic metallic parts with non-uniform surfaces and shapes. 2D materials certainly exhibit outstanding mechanical properties relative to their thickness, yet in absolute terms they are invariably brittle and easily damaged. Since continuity and integrity of anticorrosive coatings are crucial parameters for ensuring an effective and long-lasting protection of the coated subject, scratches, cracks and pinholes upon wear will reduce the commercial relevance of these coatings significantly; these issues need addressing.

As neither graphene nor hBN possess all the many diverse and sometimes conflicting properties that are required to effectively protect a metal subject in harsh environments during actual use, it is obvious to turn to hybrid coatings where the two-dimensional materials are coupled with other functional layers made of, for instance, polymers, ceramics (Sagade et al., 2017) or other materials. In this scenario, the 2D materials will provide the barrier function, while the other layers will cover other requirements. While not presenting a final solution to this complex problem, we recently demonstrated the potential of hybrid polymer-graphene coating for corrosion protections (Yu et al., 2018). Polymer films can indeed be made with vastly different physical properties, and are generally straightforward to apply to subjects through for example spin-coating, dip-casting or spray-coating. Thus, combining graphene with polymer films could lead towards effective and long-lasting coatings, where 2D materials are protected from wear- and friction-related failures while significantly improving the overall barrier properties of the coating. The general concept of multilayer hybrid coatings can easily be extended to ceramic or other inorganic materials (Ali et al., 2009, Tan et al., 2005, Figueira et al., 2015).

\subsection{Roadblocks}

For continuous, graphene-based corrosion barriers to become successful as a technology, we find that there are numerous potential challenges and roadblocks needed to be overcome:

1. Availability of continuous graphene. Availability of graphene is still limited, especially when it comes to production on large, continuous areas at reasonable costs. Today graphene can be fabricated in large amounts, as demonstrated by the Chinese manufacturer Moxi group (Xiao et al., 2016), but there is still no vendor or source of continuous sheet graphene in sizes relevant for most barrier coating applications, and certainly not at any competitive price point. While this may change in the near future, this is a serious concern for current-day businesses and investors. It is critically important to establish credible pathways to large-area, high quality graphene at a reasonable cost.

2. Large area transfer. For corrosion barrier strategies that involve transfer of graphene (Prasai et al., 2012), the transfer processes in use today are not sufficiently well-developed. While demanding substrates could include curved and rough surfaces, transfer processes even onto clean, flat surfaces are difficult without introducing damage to the graphene layer. For corrosion barriers, the coverage of graphene is obviously important, even with multilayer hybrid coatings (Yu et al., 2018) as discussed in section 2.3. The demands of high throughput, high quality, low cost for large-scale transfer process onto industrially relevant surfaces are not fulfilled at this point, even though some progress have recently been made in this direction (Morin et al., 2017).

3. Low-temperature growth. The alternative to transfer is direct growth (onto target substrate), and despite the results presented in section 2.1, it is clear that there is much more work to be done; also, the downside of direct growth is that the synthesis conditions are unlikely to be the same for 
all metals and surfaces, which suggests that a universal low-temperature synthesis strategy is not around the corner.

4. Inertia of coating industry. There is a development gap between research models and commercial models for graphene, and with a large number of barrier coating technologies on the market, introducing a novel class of technologies based on 2D materials is not straightforward. The performance of graphene coatings have to not just match, but significantly exceed any conventional coating in a certain application area or niche, to penetrate the market. Businesses that already manufacture standard coatings are unlikely to adopt radically new coatings technologies without demonstration of superior performance or lower cost, and here it is important to note that performance of a corrosion barrier technology is a lengthy process. While the price of graphene is likely to drop continuously in the coming years, it may be wise to focus on niche or high-end applications at first, where the unique properties of graphene barriers (i.e. impermeability of undamaged, continuous films) balance out the higher cost.

5. Adaptation to specific applications. Commercial barrier coatings are diverse and application specific; graphene, on the other hand, is a single material. The diversification of graphene-based barriers may be considered a challenge as well. While the totality of barrier technologies covers a very wide range of metallic, ceramic and polymer coatings with vastly different chemical and mechanical properties, graphene and hexagonal boron nitride are nearly identical materials, apart from the electrical conductivity. Here, the hybrid coatings (Yu et al., 2018) discussed in section 2.3 provides a platform for creating more specialised barrier coatings, where the function of graphene is focused on preventing diffusion between the metal and the environment.

6. Safety (especially for food packaging). As a nanomaterial, graphene is often seen as a potential hazard, and this is often unjustified. Graphene powders, sometimes used in composite coatings, are a health concern, as suspended particles in air are considered to be the most imminent risk factor (Park et al., 2017). Few-layer continuous graphene films adhering to a surface are likely to present a minimal safety issue but more research is nevertheless required to identify fragments after coating breakdown that may pose health risks.

\section{Summary}

In this topical review, we discuss recent progress on protective coatings based on graphene and hexagonal boron nitride. The activity in this research topic is substantial, as reflected by the rapidly growing number of articles, citations and patents. As per october 2018, the searchable database "google patents" yields ca. 24000 hits for "graphene transistor", and 25000 for "graphene corrosion", while "((graphene) AND ((corrosion) OR (barrier) ))" gives more than 45000. A similar pattern is found in other searchable patent databases. Despite the clear potential of 2D materials as protective coatings, a number of roadblocks and challenges must be dealt with before reaching the market (Cui et al., 2017). To the best of our knowledge, none of the continuous 2D material barrier systems prepared in laboratories offers a market-ready solution. In this review, we have focused on the obstacles keeping 2D material coatings from developing into products, as well as possible solutions to mitigate them, loosely divided in three categories. These are challenges related to the fabrication of a $2 \mathrm{D}$ coating on realistic and relevant substrates; challenges that induce failure of such ultra-thin coatings, such as poor adhesion, intercalation, delamination, galvanic corrosion, damage induced by wear and friction; and challenges that these coatings will face on the path from laboratory to commercialization. 
We find that a general route to overcome many of these issues is to combine 2D and 3D materials in hybrid or compound coatings, i.e. by combining 2D materials with polymers (Yu et al., 2018) or ceramics (Sagade et al., 2017). When embedded in a polymer coating, a 2D material may provide the barrier function, while the other layer(s) will offer other functionalities needed for an effective and longlasting protection. Such coating would have the advantages of a polymer coating (easy to apply, strong adhesion to the substrate, scratch-resistance), and protect against galvanic corrosion (when an insulating polymer is used), yet with superior barrier properties due to the presence of one or more continuous 2D sheets. In addition, with the extensive library of well-known polymer materials fitting a wide range of functionalities, even more advanced hybrid coatings than those introduced in our recent study (Yu et al., 2018) might be envisioned, combining different polymers or even ceramics with properties customised to serve different functions in the coating.

\section{Acknowledgments}

This work was supported by the innovation fund project DA-GATE (grant agreement: 12-131827). L.C. acknowledges funding by the Young Investigator Program of Villum Fonden, project no. 19130. L.C and P.B acknowledge support from the Danish National Research Foundation (DNRF) Center for Nanostructured Graphene (DNRF103).

\section{References}

AGMON, N. 1995. The grotthuss mechanism. Chemical Physics Letters, 244, 456-462.

ALI, A., AHMAD, A. \& DEEN, K. 2009. Multilayer ceramic coating for impeding corrosion of sintered NdFeB magnets. Journal of Rare Earths, 27, 1003-1007.

AMBROSI, A., BONANNI, A., SOFER, Z. \& PUMERA, M. 2013. Large-scale quantification of CVD graphene surface coverage. Nanoscale, 5, 2379-2387.

ANEJA, K. S., BOHM, S., KHANNA, A. \& BOHM, H. M. 2015. Graphene based anticorrosive coatings for $\mathrm{Cr}$ (VI) replacement. Nanoscale, 7, 17879-17888.

BAE, S., KIM, H., LEE, Y., XU, X., PARK, J.-S., ZHENG, Y., BALAKRISHNAN, J., LEI, T., KIM, H. R. \& SONG, Y. I. 2010. Roll-to-roll production of 30-inch graphene films for transparent electrodes. Nature nanotechnology, 5, 574.

BARTZ, W. J. 1971. Solid lubricant additives - effect of concentration and other additives on anti-wear performance. Wear, 17, 421-432.

BATRAKOV, K., KUZHIR, P., MAKSIMENKO, S., PADDUBSKAYA, A., VORONOVICH, S., LAMBIN, P., KAPLAS, T. \& SVIRKO, Y. 2014. Flexible transparent graphene/polymer multilayers for efficient electromagnetic field absorption. Scientific Reports, 4, 7191.

BLESMAN, A., POLONYANKIN, D. \& POSTNIKOV, D. 2015. The influence of the high temperature annealing on the small impurities segregation in J24056 grain steel. Procedia Engineering, 113, 413-417.

BUNCH, J. S., VERBRIDGE, S. S., ALDEN, J. S., VAN DER ZANDE, A. M., PARPIA, J. M., CRAIGHEAD, H. G. \& MCEUEN, P. L. 2008. Impermeable atomic membranes from graphene sheets. Nano letters, 8, 2458-2462.

BÖHM, S. 2014a. Graphene against corrosion. Nature Nanotechnology, 9, 741.

BÖHM, S. 2014b. Graphene against corrosion. Nature nanotechnology, 9, 741.

CANEVA, S., MARTIN, M.-B., D’ARSIÉ, L., ARIA, A. I., SEZEN, H., AMATI, M., GREGORATTI, L., SUGIME, H., ESCONJAUREGUI, S., ROBERTSON, J., HOFMANN, S. \& WEATHERUP, R. S. 2017. From Growth Surface to Device Interface: Preserving Metallic Fe under Monolayer Hexagonal Boron Nitride. ACS Applied Materials \& Interfaces, 9, 29973-29981. 
CASSABOISG, VALVINP \& GILB 2016. Hexagonal boron nitride is an indirect bandgap semiconductor. Nat Photon, 10, 262-266.

CHAE, S. J., GÜNEŞ, F., KIM, K. K., KIM, E. S., HAN, G. H., KIM, S. M., SHIN, H.-J., YOON, S.-M., CHOI, J.-Y., PARK, M. H., YANG, C. W., PRIBAT, D. \& LEE, Y. H. 2009. Synthesis of Large-Area Graphene Layers on Poly-Nickel Substrate by Chemical Vapor Deposition: Wrinkle Formation. Advanced Materials, 21, 2328-2333.

CHEN, S., BROWN, L., LEVENDORF, M., CAI, W., JU, S.-Y., EDGEWORTH, J., LI, X., MAGNUSON, C. W., VELAMAKANNI, A. \& PINER, R. D. 2011a. Oxidation resistance of graphene-coated $\mathrm{Cu}$ and $\mathrm{Cu} / \mathrm{Ni}$ alloy. ACS nano, 5, 1321-1327.

CHEN, X.-M., SONG, S.-H., WENG, L.-Q. \& LIU, S.-J. 2011b. Solute grain boundary segregation during high temperature plastic deformation in a Cr-Mo low alloy steel. Materials Science and Engineering: A, 528, 7663-7668.

COTTIS, R. 2010. Shreir's Corrosion, Elsevier Amsterdam.

CUI, C., LIM, A. T. O. \& HUANG, J. 2017. A cautionary note on graphene anti-corrosion coatings. Nature Nanotechnology, 12, 834.

DENG, B., LIU, Z. \& PENG, H. Toward Mass Production of CVD Graphene Films. Advanced Materials, 0, 1800996.

DUONG, D. L., HAN, G. H., LEE, S. M., GUNES, F., KIM, E. S., KIM, S. T., KIM, H., TA, Q. H., SO, K. P., YOON, S. J., CHAE, S. J., JO, Y. W., PARK, M. H., CHAE, S. H., LIM, S. C., CHOI, J. Y. \& LEE, Y. H. 2012. Probing graphene grain boundaries with optical microscopy. Nature, 490, 235-9.

FIGUEIRA, R., SILVA, C. J. \& PEREIRA, E. 2015. Organic-inorganic hybrid sol-gel coatings for metal corrosion protection: a review of recent progress. Journal of Coatings Technology and Research, 12, 135.

FILLETER, T. \& BENNEWITZ, R. 2010. Structural and frictional properties of graphene films on $\mathrm{SiC}$ (0001) studied by atomic force microscopy. Physical Review B, 81, 155412.

GALBIATI, M., STOOT, A. C., MACKENZIE, D. M. A., BØGGILD, P. \& CAMILLI, L. 2017. Real-time oxide evolution of copper protected by graphene and boron nitride barriers. Scientific Reports, 7, 39770.

GERGELY, A. 2018. A review on corrosion protection with single-layer, multilayer, and composites of graphene. Corrosion Reviews, 36, 155-225.

GERHARDUS KOCH, J. V., NEIL THOMPSON, OLIVER MOGHISSI, MELISSA GOULD, JOE PAYER 2016. International Measures of Prevention, Application, and Economics of Corrosion Technologies Study. In: JACOBSON, G. (ed.). 15835 Park Ten Place, Houston, TX 77084: Nace International.

GRÅNÄS, E., ANDERSEN, M., ARMAN, M. A., GERBER, T., HAMMER, B., SCHNADT, J., ANDERSEN, J. N., MICHELY, T. \& KNUDSEN, J. 2013. CO Intercalation of Graphene on $\operatorname{Ir}(111)$ in the Millibar Regime. The Journal of Physical Chemistry C, 117, 16438-16447.

GRÅNÄS, E., KNUDSEN, J., SCHRÖDER, U. A., GERBER, T., BUSSE, C., ARMAN, M. A., SCHULTE, K., ANDERSEN, J. N. \& MICHELY, T. 2012. Oxygen Intercalation under Graphene on Ir(111): Energetics, Kinetics, and the Role of Graphene Edges. ACS Nano, 6, 9951-9963.

HAGEN, C. H. M., KRISTOFFERSEN, A. \& KNUDSEN, Ø. 2016. The Effect of Surface Profile on Coating Adhesion and Corrosion Resistance. CORROSION 2016. Vancouver, British Columbia, Canada: NACE International.

HOBBINS, N. D. \& ROBERTS, R. F. 1983. Copper corrosion inhibitor. Google Patents.

HONG, J., LEE, S., LEE, S., HAN, H., MAHATA, C., YEON, H.-W., KOO, B., KIM, S.-I., NAM, T. \& BYUN, K. 2014. Graphene as an atomically thin barrier to Cu diffusion into Si. Nanoscale, 6, 7503-7511.

HONG, S. H., SEO, M. G., JANG, C. H. \& LEE, K. S. 2015. Evaluation of the Effects of Thermal Aging of Austenitic Stainless Steel Welds Using Small Punch Test. Procedia Engineering, 130, 1010-1018.

HSIEH, Y.-P., HOFMANN, M., CHANG, K.-W., JHU, J. G., LI, Y.-Y., CHEN, K. Y., YANG, C. C., CHANG, W.-S. \& CHEN, L.-C. 2013. Complete corrosion inhibition through graphene defect passivation. ACS nano, 8, 443-448.

HUANG, C.-Y., LIU, X.-J., CHANG, Y.-S., CHEN, C.-H. \& LEE, Y.-L. 2017. The Effect of Surface Pretreatment on the Corrosion Performance of Graphene Coatings on 6061 Aluminum Alloy. ECS Transactions, 77, 693-703. 
HUH, J.-H., KIM, S. H., CHU, J. H., KIM, S. Y., KIM, J. H. \& KWON, S.-Y. 2014. Enhancement of seawater corrosion resistance in copper using acetone-derived graphene coating. Nanoscale, 6, 4379-4386.

HUSAIN, E., NARAYANAN, T. N., TAHA-TIJERINA, J. J., VINOD, S., VAJTAI, R. \& AJAYAN, P. M. 2013. Marine corrosion protective coatings of hexagonal boron nitride thin films on stainless steel. ACS Appl Mater Interfaces, 5, 4129-35.

JON IVERSEN, F. A., ADAM STOOT, FENG YU, LINE KYHL, SUSANNE HALKJÆR, JACQUES CHEVALLIER, PETER BØGGILD, LIV HORNEKAER, LUCA CAMILLI, ANDREW CASSIDY 2018. Low-temperature synthesis of a graphene-based, corrosion-inhibiting coating on an industrial grade alloy. Corrosion Science, submitted.

KEIL, P., FRAHM, R. \& LÜTZENKIRCHEN-HECHT, D. 2010. Native oxidation of sputter deposited polycrystalline copper thin films during short and long exposure times: Comparative investigation by specular and non-specular grazing incidence X-ray absorption spectroscopy. Corrosion Science, 52, 13051316.

KIDAMBI, P. R., BAYER, B. C., BLUME, R., WANG, Z. J., BAEHTZ, C., WEATHERUP, R. S., WILLINGER, M. G., SCHLOEGL, R. \& HOFMANN, S. 2013. Observing graphene grow: catalystgraphene interactions during scalable graphene growth on polycrystalline copper. Nano Lett, 13, 4769-78.

KIM, J., ISHIHARA, M., KOGA, Y., TSUGAWA, K., HASEGAWA, M. \& IIJIMA, S. 2011a. Low-temperature synthesis of large-area graphene-based transparent conductive films using surface wave plasma chemical vapor deposition. Applied Physics Letters, 98, 091502.

KIM, K.-S., LEE, H.-J., LEE, C., LEE, S.-K., JANG, H., AHN, J.-H., KIM, J.-H. \& LEE, H.-J. 2011b. Chemical Vapor Deposition-Grown Graphene: The Thinnest Solid Lubricant. ACS Nano, 5, 5107-5114.

KIRKLAND, N., SCHILLER, T., MEDHEKAR, N. \& BIRBILIS, N. 2012. Exploring graphene as a corrosion protection barrier. Corrosion Science, 56, 1-4.

KYHL, L., BALOG, R., CASSIDY, A., JØRGENSEN, J., GRUBISIC-ČABO, A., TROTOCHAUD, L., BLUHM, H. \& HORNEKÆR, L. 2018. Enhancing Graphene Protective Coatings by Hydrogen-Induced Chemical Bond Formation. ACS Applied Nano Materials.

KYHL, L., NIELSEN, S. F., ČABO, A. G., CASSIDY, A., MIWA, J. A. \& HORNEKÆR, L. 2015. Graphene as an anti-corrosion coating layer. Faraday discussions, 180, 495-509.

LARCIPRETE, R., ULSTRUP, S., LACOVIG, P., DALMIGLIO, M., BIANCHI, M., MAZZOLA, F., HORNEKÆR, L., ORLANDO, F., BARALDI, A., HOFMANN, P. \& LIZZIT, S. 2012. Oxygen Switching of the Epitaxial Graphene-Metal Interaction. ACS Nano, 6, 9551-9558.

LEE, C., LI, Q., KALB, W., LIU, X.-Z., BERGER, H., CARPICK, R. W. \& HONE, J. 2010. Frictional Characteristics of Atomically Thin Sheets. Science, 328, 76-80.

LEE, C., WEI, X., KYSAR, J. W. \& HONE, J. 2008. Measurement of the Elastic Properties and Intrinsic Strength of Monolayer Graphene. Science, 321, 385-388.

LEE, C., WEI, X., LI, Q., CARPICK, R., KYSAR, J. W. \& HONE, J. 2009a. Elastic and frictional properties of graphene. physica status solidi (b), 246, 2562-2567.

LEE, H., LEE, N., SEO, Y., EOM, J. \& LEE, S. 2009b. Comparison of frictional forces on graphene and graphite. Nanotechnology, 20, 325701.

LEE, J.-H., LEE, E. K., JOO, W.-J., JANG, Y., KIM, B.-S., LIM, J. Y., CHOI, S.-H., AHN, S. J., AHN, J. R. \& PARK, M.-H. 2014. Wafer-scale growth of single-crystal monolayer graphene on reusable hydrogenterminated germanium. Science, 344, 286-289.

LI, J., WANG, X.-Y., LIU, X.-R., JIN, Z., WANG, D. \& WAN, L.-J. 2015. Facile growth of centimeter-sized single-crystal graphene on copper foil at atmospheric pressure. Journal of Materials Chemistry C, 3, 3530-3535.

LI, L. H., CERVENKA, J., WATANABE, K., TANIGUCHI, T. \& CHEN, Y. 2014a. Strong Oxidation Resistance of Atomically Thin Boron Nitride Nanosheets. ACS Nano, 8, 1457-1462.

LI, Q., LEE, C., CARPICK, R. W. \& HONE, J. 2010. Substrate effect on thickness - dependent friction on graphene. physica status solidi (b), 247, 2909-2914.

LI, S., LI, Q., CARPICK, R. W., GUMBSCH, P., LIU, X. Z., DING, X., SUN, J. \& LI, J. 2016. The evolving quality of frictional contact with graphene. Nature, 539, 541. 
LI, X., CAI, W., AN, J., KIM, S., NAH, J., YANG, D., PINER, R., VELAMAKANNI, A., JUNG, I., TUTUC, E., BANERJEE, S. K., COLOMBO, L. \& RUOFF, R. S. 2009. Large-area synthesis of high-quality and uniform graphene films on copper foils. Science, 324, 1312-4.

LI, X., YIN, J., ZHOU, J. \& GUO, W. 2014b. Large area hexagonal boron nitride monolayer as efficient atomically thick insulating coating against friction and oxidation. Nanotechnology, 25, 105701.

LI, Z., WU, P., WANG, C., FAN, X., ZHANG, W., ZHAI, X., ZENG, C., LI, Z., YANG, J. \& HOU, J. 2011. Low-temperature growth of graphene by chemical vapor deposition using solid and liquid carbon sources. ACS nano, 5, 3385-3390.

LIN, L., DENG, B., SUN, J., PENG, H. \& LIU, Z. 2018. Bridging the Gap between Reality and Ideal in Chemical Vapor Deposition Growth of Graphene. Chemical Reviews.

LIU, Z., GONG, Y., ZHOU, W., MA, L., YU, J., IDROBO, J. C., JUNG, J., MACDONALD, A. H., VAJTAI, R., LOU, J. \& AJAYAN, P. M. 2013. Ultrathin high-temperature oxidation-resistant coatings of hexagonal boron nitride. Nature Communications, 4, 2541.

LONGWITZ, S. R., SCHNADT, J., VESTERGAARD, E. K., VANG, R. T., STENSGAARD, I., BRUNE, H. \& BESENBACHER, F. 2004. High-Coverage Structures of Carbon Monoxide Adsorbed on Pt(111) Studied by High-Pressure Scanning Tunneling Microscopy. The Journal of Physical Chemistry B, 108, 1449714502.

LUO, B., GAO, E., GENG, D., WANG, H., XU, Z. \& YU, G. 2017. Etching-Controlled Growth of Graphene by Chemical Vapor Deposition. Chemistry of Materials, 29, 1022-1027.

LUO, B., WHELAN, P. R., SHIVAYOGIMATH, A., MACKENZIE, D. M. A., BØGGILD, P. \& BOOTH, T. J. 2016. Copper Oxidation through Nucleation Sites of Chemical Vapor Deposited Graphene. Chemistry of Materials, 28, 3789-3795.

LUO, Z., LU, Y., SINGER, D. W., BERCK, M. E., SOMERS, L. A., GOLDSMITH, B. R. \& JOHNSON, A. C. 2011. Effect of substrate roughness and feedstock concentration on growth of wafer-scale graphene at atmospheric pressure. Chemistry of Materials, 23, 1441-1447.

MCCAFFERTY, E. 2005. Validation of corrosion rates measured by the Tafel extrapolation method. Corrosion science, 47, 3202-3215.

MING, H., WANG, J., ZHANG, Z., WANG, S., HAN, E.-H. \& KE, W. 2014. Multilayer graphene: a potential anti-oxidation barrier in simulated primary water. Journal of Materials Science \& Technology, 30, 10841087.

MIŠKOVIĆ-STANKOVIĆ, V., JEVREMOVIĆ, I., JUNG, I. \& RHEE, K. 2014. Electrochemical study of corrosion behavior of graphene coatings on copper and aluminum in a chloride solution. Carbon, 75, 335344.

MORIN, J. L. P., DUBEY, N., DECROIX, F. E. D., LUONG-VAN, E. K., NETO, A. H. C. \& ROSA, V. 2017. Graphene transfer to 3-dimensional surfaces: a vacuum-assisted dry transfer method. 2D Materials, 4, 025060.

MUÑOZ, R. \& GÓMEZ - ALEIXANDRE, C. 2013. Review of CVD synthesis of graphene. Chemical Vapor Deposition, 19, 297-322.

NAKAYA, M., UEDONO, A. \& HOTTA, A. 2015. Recent progress in gas barrier thin film coatings on PET bottles in food and beverage applications. Coatings, 5, 987-1001.

NILSSON, L., ANDERSEN, M., BALOG, R., LÆGSGAARD, E., HOFMANN, P., BESENBACHER, F., HAMMER, B., STENSGAARD, I. \& HORNEKÆR, L. 2012. Graphene Coatings: Probing the Limits of the One Atom Thick Protection Layer. ACS Nano, 6, 10258-10266.

NILSSON, L., ANDERSEN, M., HAMMER, B., STENSGAARD, I. \& HORNEKÆR, L. 2013. Breakdown of the Graphene Coating Effect under Sequential Exposure to O2 and H2S. The Journal of Physical Chemistry Letters, 4, 3770-3774.

NINE, M. J., COLE, M. A., TRAN, D. N. H. \& LOSIC, D. 2015a. Graphene: a multipurpose material for protective coatings. Journal of Materials Chemistry A, 3, 12580-12602.

NINE, M. J., COLE, M. A., TRAN, D. N. H. \& LOSIC, D. 2015b. Graphene: a multipurpose material for protective coatings. J. Mater. Chem. A, 3, 12580-12602.

NOVOSELOV, K. S., GEIM, A. K., MOROZOV, S. V., JIANG, D., ZHANG, Y., DUBONOS, S. V., GRIGORIEVA, I. V. \& FIRSOV, A. A. 2004. Electric field effect in atomically thin carbon films. Science, 306, 666-669. 
OLDFIELD, J. W. 1988. Electrochemical theory of galvanic corrosion. Galvanic Corrosion. ASTM International.

PARK, M. V., BLEEKER, E. A., BRAND, W., CASSEE, F. R., VAN ELK, M., GOSENS, I., DE JONG, W. H., MEESTERS, J. A., PEIJNENBURG, W. J. \& QUIK, J. T. 2017. Considerations for safe innovation: the case of Graphene. ACS nano, 11, 9574-9593.

POURBAIX, M. \& STAEHLE, R. W. 1973. Electrochemical Equilibria. Lectures on Electrochemical Corrosion. Springer.

PRASAI, D., TUBERQUIA, J. C., HARL, R. R., JENNINGS, G. K. \& BOLOTIN, K. I. 2012. Graphene: corrosion-inhibiting coating. ACS nano, 6, 1102-1108.

PU, N.-W., SHI, G.-N., LIU, Y.-M., SUN, X., CHANG, J.-K., SUN, C.-L., GER, M.-D., CHEN, C.-Y., WANG, P.-C., PENG, Y.-Y., WU, C.-H. \& LAWES, S. 2015. Graphene grown on stainless steel as a highperformance and ecofriendly anti-corrosion coating for polymer electrolyte membrane fuel cell bipolar plates. Journal of Power Sources, 282, 248-256.

REVIE, R. W. 2008. Corrosion and corrosion control: an introduction to corrosion science and engineering, John Wiley \& Sons.

RUAN, G., SUN, Z., PENG, Z. \& TOUR, J. M. 2011. Growth of graphene from food, insects, and waste. ACS nano, 5, 7601-7607.

SAGADE, A. A., ARIA, A. I., EDGE, S., MELGARI, P., GIESEKING, B., BAYER, B. C., MEYER, J. C., BIRD, D., BREWER, P. \& HOFMANN, S. 2017. Graphene-based nanolaminates as ultra-high permeation barriers. npj 2D Materials and Applications, 1, 35.

SAHU, S. C., SAMANTARA, A. K., SETH, M., PARWAIZ, S., SINGH, B. P., RATH, P. C. \& JENA, B. K. 2013. A facile electrochemical approach for development of highly corrosion protective coatings using graphene nanosheets. Electrochemistry Communications, 32, 22-26.

SCHRIVER, M., REGAN, W., GANNETT, W. J., ZANIEWSKI, A. M., CROMMIE, M. F. \& ZETTL, A. 2013. Graphene as a long-term metal oxidation barrier: worse than nothing. ACS nano, 7, 5763-5768.

SHEN, L., ZHAO, Y., WANG, Y., SONG, R., YAO, Q., CHEN, S. \& CHAI, Y. 2016. A long-term corrosion barrier with an insulating boron nitride monolayer. Journal of Materials Chemistry A, 4, 5044-5050.

SHIN, Y. J., STROMBERG, R., NAY, R., HUANG, H., WEE, A. T. S., YANG, H. \& BHATIA, C. S. 2011. Carbon, 49, 4059-4073.

SHINOHARA, H. \& TIWARI, A. 2015. Graphene: an introduction to the fundamentals and industrial applications, John Wiley \& Sons.

SHREIR, L. L. 2013. Corrosion: corrosion control, Newnes.

SINGH RAMAN, R. K., CHAKRABORTY BANERJEE, P., LOBO, D. E., GULLAPALLI, H., SUMANDASA, M., KUMAR, A., CHOUDHARY, L., TKACZ, R., AJAYAN, P. M. \& MAJUMDER, M. 2012. Protecting copper from electrochemical degradation by graphene coating. Carbon, 50, 4040-4045.

SINGH, V., JOUNG, D., ZHAI, L., DAS, S., KHONDAKER, S. I. \& SEAL, S. 2011. Graphene based materials: past, present and future. Progress in materials science, 56, 1178-1271.

SLOAN, F. \& TALBOT, J. 1992. Corrosion of graphite-fiber-reinforced composites I — Galvanic coupling damage. Corrosion, 48, 830-838.

SREEVATSA, S., BANERJEE, A. \& HAIM, G. 2009. Graphene as a permeable ionic barrier. ECS Transactions, 19, 259-264.

STOOT, A. C., CAMILLI, L., SPIEGELHAUER, S.-A., YU, F. \& BØGGILD, P. 2015. Multilayer graphene for long-term corrosion protection of stainless steel bipolar plates for polymer electrolyte membrane fuel cell. Journal of Power Sources, 293, 846-851.

SUN, Z., YAN, Z., YAO, J., BEITLER, E., ZHU, Y. \& TOUR, J. M. 2010. Growth of graphene from solid carbon sources. Nature, 468, 549.

SØRENSEN, P. A., KIIL, S., DAM-JOHANSEN, K. \& WEINELL, C. E. 2009a. Anticorrosive coatings: a review. Journal of Coatings Technology and Research, 6, 135-176.

SØRENSEN, P. A., KIIL, S., DAM-JOHANSEN, K. \& WEINELL, C. E. 2009b. Influence of substrate topography on cathodic delamination of anticorrosive coatings. Progress in Organic Coatings, 64, 142149.

TAN, A., SOUTAR, A., ANNERGREN, I. \& LIU, Y. 2005. Multilayer sol-gel coatings for corrosion protection of magnesium. Surface and coatings technology, 198, 478-482. 
TAO, L., LEE, J., HOLT, M., CHOU, H., MCDONNELL, S. J., FERRER, D. A., BABENCO, M. G., WALLACE, R. M., BANERJEE, S. K. \& RUOFF, R. S. 2012. Uniform wafer-scale chemical vapor deposition of graphene on evaporated $\mathrm{Cu}$ (111) film with quality comparable to exfoliated monolayer. The Journal of Physical Chemistry C, 116, 24068-24074.

TUCKER, W. C., BROWN, R. \& RUSSELL, L. 1990. Corrosion between a graphite/polymer composite and metals. Journal of Composite Materials, 24, 92-102.

TWITE, R. \& BIERWAGEN, G. 1998. Review of alternatives to chromate for corrosion protection of aluminum aerospace alloys. Progress in organic coatings, 33, 91-100.

WEATHERUP, R. S., BAYER, B. C., BLUME, R., DUCATI, C., BAEHTZ, C., SCHLÖGL, R. \& HOFMANN, S. 2011. In Situ Characterization of Alloy Catalysts for Low-Temperature Graphene Growth. Nano Letters, 11, 4154-4160.

WEATHERUP, R. S., D’ARSIÉ, L., CABRERO-VILATELA, A., CANEVA, S., BLUME, R., ROBERTSON, J., SCHLOEGL, R. \& HOFMANN, S. 2015. Long-Term Passivation of Strongly Interacting Metals with Single-Layer Graphene. Journal of the American Chemical Society, 137, 14358-14366.

WU, T., DING, G., SHEN, H., WANG, H., SUN, L., ZHU, Y., JIANG, D. \& XIE, X. 2013. Continuous graphene films synthesized at low temperatures by introducing coronene as nucleation seeds. Nanoscale, 5, 54565461.

WU, W., JAUREGUI, L. A., SU, Z., LIU, Z., BAO, J., CHEN, Y. P. \& YU, Q. 2011. Growth of single crystal graphene arrays by locally controlling nucleation on polycrystalline $\mathrm{Cu}$ using chemical vapor deposition. Advanced materials, 23, 4898-4903.

XIAO, X., LI, Y. \& LIU, Z. 2016. Graphene commercialization. Nature Materials, 15, 697.

XU, C., DU, L., YANG, B. \& ZHANG, W. 2011. The effect of Al content on the galvanic corrosion behaviour of coupled Ni/graphite and $\mathrm{Ni}-\mathrm{Al}$ coatings. Corrosion Science, 53, 2066-2074.

YE, X. H., YU, F., CURIONI, M., LIN, Z., ZHANG, H. J., ZHU, H. W., LIU, Z. \& ZHONG, M. L. 2015. Corrosion resistance of graphene directly and locally grown on bulk nickel substrate by laser irradiation. RSC Adv., 5, 35384-35390.

YIVLIALIN, R., BUSSETTI, G., DUÒ, L., YU, F., GALBIATI, M. \& CAMILLI, L. 2018. CVD Graphene/Ni Interface Evolution in Sulfuric Electrolyte. Langmuir, 34, 3413-3419.

YOO, B. M., SHIN, H. J., YOON, H. W. \& PARK, H. B. 2014. Graphene and graphene oxide and their uses in barrier polymers. Journal of Applied Polymer Science, 131, n/a-n/a.

YU, F., CAMILLI, L., WANG, T., MACKENZIE, D. M. A., CURIONI, M., AKID, R. \& BØGGILD, P. 2018. Complete long-term corrosion protection with chemical vapor deposited graphene. Carbon, 132, 78-84.

YU, F., STOOT, A. C., BØGGILD, P. \& CAMILLI, L. 2016. Failure of multi-layer graphene coatings in acidic media. RSC Advances, 6, 21497-21502.

ZAHRAN, R., IBRAHIM, I. \& SEDAHMED, G. 1996. The corrosion of graphite/copper composites in different aqueous environments. Materials Letters, 28, 237-244.

ZHANG, A., LIU, D. \& WANG, H. 2013a. Effect of thermal exposure on microstructure and tensile properties of laser deposited Ti60A alloy. Materials Science and Engineering: A, 562, 61-68.

ZHANG, H., REN, S., PU, J. \& XUE, Q. 2018. Barrier mechanism of multilayers graphene coated copper against atomic oxygen irradiation. Applied Surface Science, 444, 28-35.

ZHANG, Y., FU, Q., CUI, Y., MU, R., JIN, L. \& BAO, X. 2013b. Enhanced reactivity of graphene wrinkles and their function as nanosized gas inlets for reactions under graphene. Physical Chemistry Chemical Physics, 15, 19042-19048.

ZHANG, Y., ZHANG, H., WANG, B., CHEN, Z., ZHANG, Y., WANG, B., SUI, Y., ZHU, B., TANG, C. \& LI, X. 2014a. Role of wrinkles in the corrosion of graphene domain-coated $\mathrm{Cu}$ surfaces. Applied Physics Letters, 104, 143110.

ZHANG, Y., ZHANG, L. \& ZHOU, C. 2013c. Review of chemical vapor deposition of graphene and related applications. Accounts of chemical research, 46, 2329-2339.

ZHANG, Y. H., WANG, B., ZHANG, H. R., CHEN, Z. Y., ZHANG, Y. Q., WANG, B., SUI, Y. P., LI, X. L., XIE, X. M., YU, G. H., JIN, Z. \& LIU, X. Y. 2014b. The distribution of wrinkles and their effects on the oxidation resistance of chemical vapor deposition graphene. Carbon, 70, 81-86.

ZHAO, Y., WU, X., YANG, J. \& ZENG, X. C. 2012. Oxidation of a two-dimensional hexagonal boron nitride monolayer: a first-principles study. Physical Chemistry Chemical Physics, 14, 5545-5550. 
ZHOU, F., LI, Z., SHENOY, G. J., LI, L. \& LIU, H. 2013a. Enhanced room-temperature corrosion of copper in the presence of graphene. ACS nano, 7, 6939-6947.

ZHOU, H., YU, W. J., LIU, L., CHENG, R., CHEN, Y., HUANG, X., LIU, Y., WANG, Y., HUANG, Y. \& DUAN, X. 2013b. Chemical vapour deposition growth of large single crystals of monolayer and bilayer graphene. Nature communications, 4, 2096.

ZHOU, Y., CHEN, W., CUI, P., ZENG, J., LIN, Z., KAXIRAS, E. \& ZHANG, Z. 2016. Enhancing the Hydrogen Activation Reactivity of Nonprecious Metal Substrates via Confined Catalysis Underneath Graphene. Nano Letters, 16, 6058-6063. 